Document downloaded from:

http://hdl.handle.net/10251/64813

This paper must be cited as:

Payri González, F.; Olmeda González, PC.; Martín Díaz, J.; Carreño, R. (2015).

Experimental analysis of the global energy balance in a DI diesel engine. Applied Thermal Engineering. 89:545-557. doi:10.1016/j.applthermaleng.2015.06.005.

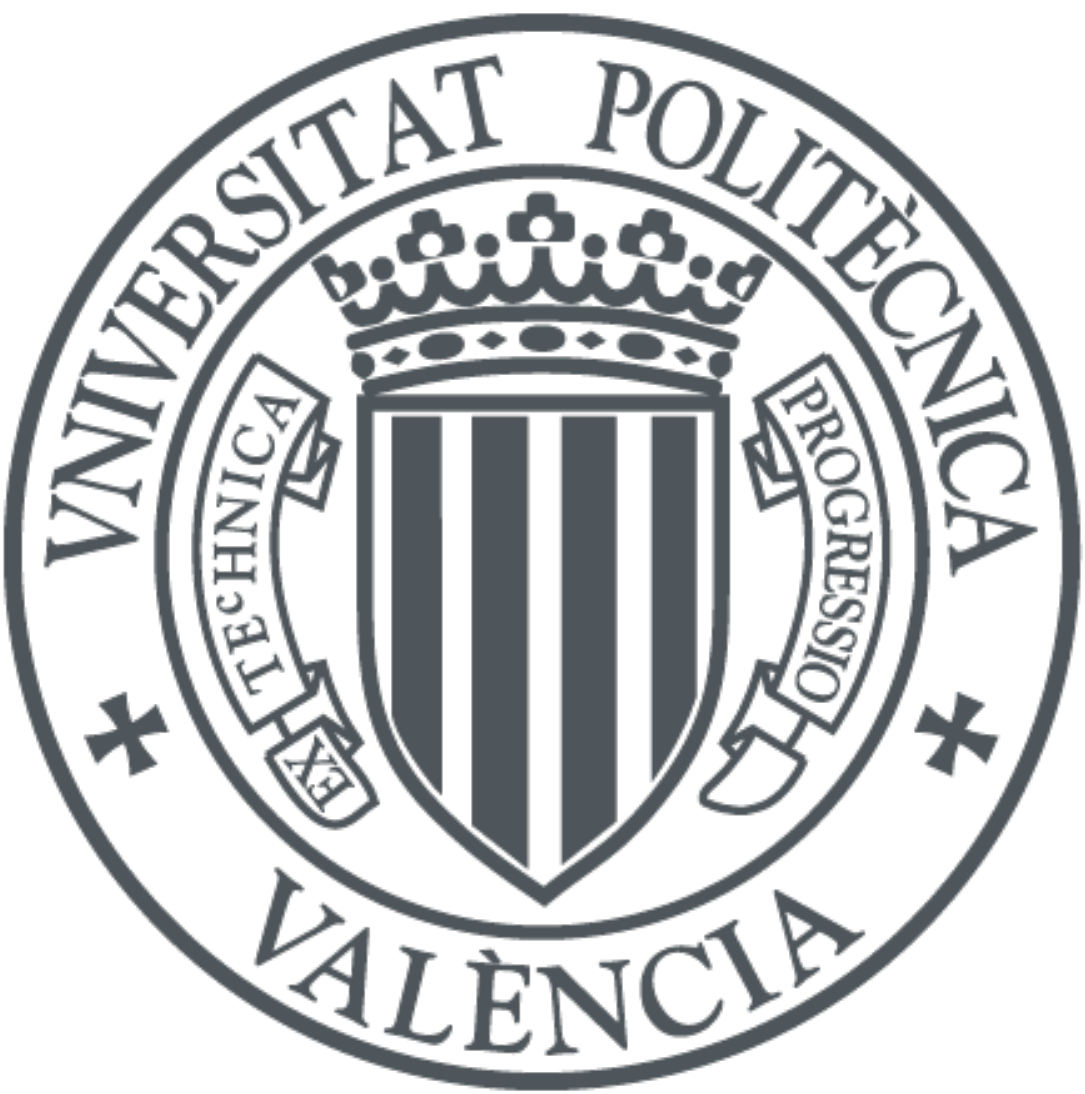

The final publication is available at

http://dx.doi.org/10.1016/j.applthermaleng.2015.06.005

Copyright Elsevier

Additional Information 


\title{
Experimental analysis of the global energy balance in a DI Diesel engine
}

\author{
Francisco Payri, Pablo Olmeda, Jaime Martín*, Ricardo Carreño \\ CMT-Motores Térmicos, Universitat Politècnica de València, Camino de Vera s/n, 46022, Valencia, Spain
}

\begin{abstract}
The increasingly stringent internal combustion engines (ICE) emissions regulations, has led to the extended use of after-treatment systems, giving progressively more importance to the engine efficiency optimization. In this context, the experimental methodologies to perform and analyse the energy balance show as a key issue to evaluate the potential of different engine strategies aimed at the consumption optimization and the improvement paths identification. This works deals with the complete description of an experimental energy balance tool, including the comprehensive description of the specific designed experimental installation used to the determination of each energy term involved in the energy balance. After the tool description, a study of the energy balance in the engine map of a DI Diesel engine was carried out, with the objective of determining the engine speed and load influence on each energy term. A subsequent parametric study varying the coolant temperature, the intake air temperature and the start of the injection (SOI) and their influence in the engine efficiency has been performed. The results shows that the variation of the coolant temperature has an almost negligible effect in terms of efficiency whilst cooling the air yields in an improvement about $1 \%$ and advancing the SOI about $1.5 \%$.

Keywords: Energy balance, Diesel engines, Heat transfer, Consumption reduction
\end{abstract}

${ }^{*}$ Corresponding author. Tel: +34963877650 ; fax: +34963877659

Email address: jaimardi@mot.upv.es (Jaime Martín)

URL: www. cmt.upv.es (Jaime Martín) 


\section{Nomenclature}

\begin{tabular}{|c|c|}
\hline$c_{p}$ & Specific heat at constant pressure $\ldots \ldots \ldots \ldots \ldots \ldots$ \\
\hline$\dot{H}_{b b}$ & Blow-by sensible enthalpy flow ....... \\
\hline$\dot{H}_{g}$ & Net sensible enthalpy flow of exhaust gases $\ldots \ldots \ldots[W],\left[\% m_{f} H v\right]$ \\
\hline$H_{v}$ & Heating value $\ldots . . \ldots$ \\
\hline$\dot{m}$ & Mass flow rate...$\ldots$. \\
\hline$N_{e}$ & Indicated efficiency $\ldots \ldots \ldots \ldots \ldots$ \\
\hline$\eta_{b}$ & Brake efficiency $\ldots \ldots \ldots \ldots \ldots$ \\
\hline$\eta_{i}$ & Brake power $\ldots \ldots \ldots \ldots \ldots$ \\
\hline$\eta_{m}$ & Mechanical efficiency $\left.\ldots \ldots \ldots \ldots \ldots \ldots \ldots \ldots \ldots \ldots \ldots m_{f} H v\right]$ \\
\hline$p$ & In-cylinder pressure $\ldots \ldots \ldots \ldots$ \\
\hline$\dot{Q}_{a}$ & Heat transfer in the intercooler $\ldots \ldots \ldots \ldots \ldots \ldots \ldots[W],\left[\% m_{f} H v\right]$ \\
\hline$\dot{Q}_{\text {cool }}$ & Heat transfer to the coolant $\ldots \ldots \ldots \ldots \ldots \ldots \ldots[W],\left[\% m_{f} H v\right]$ \\
\hline$\dot{Q}_{E G R}$ & Heat transfer in the EGR cooler $\ldots \ldots \ldots \ldots \ldots \ldots \ldots[W],\left[\% m_{f} H v\right]$ \\
\hline$\dot{Q}_{\text {ext }}$ & Heat transfer to the ambient $\ldots \ldots \ldots \ldots \ldots \ldots \ldots[W],\left[\% m_{f} H v\right]$ \\
\hline$\dot{H}_{i c}$ & Incomplete combustion losses $\ldots \ldots \ldots \ldots \ldots \ldots[W],\left[\% m_{f} H v\right]$ \\
\hline$\dot{Q}_{m i s c}$ & Miscellaneous energy term $\ldots \ldots \ldots \ldots \ldots \ldots \ldots[W],\left[\% m_{f} H v\right]$ \\
\hline$\dot{Q}_{\text {oil }}$ & Heat transfer to the engine body oil in the engine block $[W],\left[\% m_{f} H v\right]$ \\
\hline$\dot{Q}_{\text {turbo }}$ & Heat transfer to the turbocharger oil $\ldots \ldots \ldots \ldots \ldots[W],\left[\% m_{f} H v\right]$ \\
\hline$\dot{Q}_{\text {unbal }}$ & Experimental unbalance $\ldots \ldots \ldots \ldots \ldots \ldots \ldots \ldots[W],\left[\% m_{f} H v\right]$ \\
\hline$T$ & Temperature ... \\
\hline$V$ & 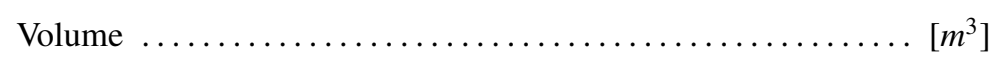 \\
\hline
\end{tabular}




Abbreviations
$\begin{array}{ll}\text { CI } & \text { Compression ignition } \\ \text { DI } & \text { Direct injection } \\ \text { ECU } & \text { Engine control unit } \\ \text { EGR } & \text { Exhaust Gases Recirculation } \\ \text { EVO } & \text { Exhaust Valve Open } \\ \text { GEB } & \text { Global Energy Balance } \\ \text { HT } & \text { Heat Transfer } \\ \text { ICE } & \text { Internal Combustion Engine } \\ \text { PID } & \text { Proportional-Integral-Derivative controller } \\ \text { RTD } & \text { Resistance Temperature Detectors } \\ \text { SI } & \text { Spark ignition } \\ \text { SOI } & \text { Start Of Injection } \\ \text { TDC } & \text { Top Dead Centre }\end{array}$




\section{Introduction}

Despite of the very stringent emissions regulations that have been imposed in the last years, the most widespread technology in the automotive sector are still the Internal Combustion Engines (ICE). With the purpose of meeting those regulations, in the last two decades the engine research has been mainly focused on reducing the pollutant emissions by means of different techniques oriented to limit the pollutant formation during the combustion process or reducing the engine tailpipe emissions. New research aimed at the reduction of the $N O_{x}$ and soot emissions as well as the improvement of the engine efficiency by implementing different engine strategies or technologies can be found in the literature. Since the injection setting and the combustion process have a close relationship, several works related to the analysis of the injection strategies [1], the effect of high injection pressure [2] and multiple injections [3] has been carried out. The air management has also been subject of multiple research, either by using high boost pressure [4] or generating high swirl [5,6] and tumble ratios [7]. With the purpose of accomplish the emission regulations, some strategies such as the use of exhaust gases recirculation (EGR) [8,9], variable timing [10, 11], new engine control systems [12] or cleaner fuels [13, 14] have also been in the focus of the recent research. However, to comply with the current as well as the upcoming stringent emissions regulations, the use of after treatment systems is still a general practice in the automotive industry $[15,16]$. Since further $N O_{x}$ and soot reduction is a barely attainable task using internal strategies. This fact along with the growing regulatory pressure to reduce Greenhouse Gases (GHG), in particular CO2 [17], has revitalized the interest of the automotive sector on the optimization of engine thermo-fluiddynamic processes to improve the fuel consumption.

Although alternative non ICE-based powertrains are being evaluated, the ICE has still room to increase its efficiency and reduce its GHG emissions in traditional or Hybrid Electric powertrains, remaining a cost-effective solution for the transport sector. Hence, the efforts are oriented to different issues such as thermal management [18, 19], indicated cycle optimization [20], in-cylinder heat transfer (HT) reduction [21, 22], engine downsizing [7], friction reduction by means of low viscosity lubricating oil [23] and piston coatings [24], or assessing the mechanical losses in the turbocharger [25] among others.

To evaluate the improvement achieved by means of a specific engine strategy, the use of Global Energy Balances (GEB) is a useful tool for identifying the paths followed by the chemical energy of the fuel until reaching the final destinations. The identification of this repartition allows determining the effect on different processes inherent to ICE operation such as cooling, lubricating, fuel injection, heat transfer, mechanical losses or air management. Therefore, cost-benefit can be evaluated and further improvements alternatives developed. Different works dealing with experimental GEB can be found in literature, for engines in conventional operation [26], running at stoichiometric conditions [27], with piston coating [22], or operating with alternative fuels [28, 29]. Usually, the basis of those analyses is the first law of thermodynamics, while the most usual approach takes into account three major terms in 
the GEB: the brake power, the cooling losses and the exhaust gas losses. A miscellanea term can also be included to consider undetermined energy losses with a minor impact or difficult to measure, such as heat rejection to the ambient, blow-by enthalpy and unburned fuel[15, 22]. Thus, in the simplest approach, a very limited number of variables are required to carry out the GEB. However, if a rigorous description of the energy transformation is required, a more specific installation and analysis must be done. Hence, some terms are divided in this work in detail: the indicated power is split into mechanical losses (pumping, friction and auxiliary losses) and brake power, and the heat losses are split into heat transfer (HT) to the coolant, block oil, turbocharger oil, intercooler and EGR exchanger.

With the objective of performing a detailed GEB, important modifications were carried out in the original coolant and oil circuits of the engine. The complete description of the test cell and the required modifications of the engine are firstly described; later, some examples of the use of the experimental set-up to analyse the effect of some parameter variation on the energy repartition will be shown. As a starting point, a speed and load sweeps (complete engine map) are carried out, aimed at the identification and analysis of the most important trends in the energy split. Then, some parametric studies including the variation of coolant temperature, intake air temperature and the start of injection time (SOI) are performed with the intention of identifying the effect of these parameters on the energy repartition and the sensitivity of the engine efficiency to these variables. Finally, a discussion of the results regarding the potential of the GEB to evaluate different engine strategies is presented.

\section{Experimental setup}

The research was carried out in a DI Diesel Engine, whose main characteristics are presented in Table 1. To reproduce the repartition of the energy at each sub-system in real operation, a multi-cylinder engine was used, in spite of the drawback of a more difficult control and possible cylinder dispersion [30] in comparison with a single cylinder engine. Some modifications were carried out in the original engine systems, to attain a better control of the engine operation parameters and to perform the experimental measurements. Hence, the original coolant and oil circuits were adapted to measure the heat rejection to the coolant, block oil and turbocharger oil independently.

Apart from the engine control systems, the test cell includes specific instrumentation for the detailed and accurate heat rejection analysis. The technical characteristics of the test cell instrumentation are presented in Table 2 , and the test cells layouts are shown in Figure 1 and 2. The installation was prepared, on the one hand, to acquire the standard data necessary to perform the combustion diagnosis (Figure 1) and on the other hand, to acquire the data required for the energy balances (Figure 2). Thus, the in-cylinder pressure, some mean variables such as air and fuel mass flows, gas temperatures and pressures at different intake and exhaust positions and some liquids (oil and coolant) mass flows and temperatures, were measured. 
To measure the in-cylinder pressure, an AVL GH13P piezo-electric transducer was installed at the glow plug hole of each cylinder. The signal provided by the piezo-electric transducer was conditioned by means of a Kistler 5011B amplifier and the digital processing was performed following the method described in [31]. To ensure the accuracy of the pressure signal obtained, the pressure sensor was calibrated according to the traditional method proposed in [32], as well as a home-developed methodology [33] to determine some experimental and engine uncertainties (pressure pegging, TDC position, compression ratio and so on) was applied.

The mean temperature of the gases was measured by means of K-type thermocouples or Resistance Temperature Detectors (RTD) depending on the accuracy requirement, whilst the mean pressures were measured with piezoresistive pressure transmitters. The determination of the gases and fuel mass flows is necessary to control the combustion process and it is important to analyse the HT processes in the chamber. The injected fuel, the air flow and the blow-by leakage were measured with an AVL 733S Fuel meter, a DN80 sensiflow and an AVL blow-by Meter respectively. The exhaust emissions were analysed using an exhaust monitoring equipment (Horiba MEXA 7100 DEGR), which also allowed to measuring the $\mathrm{CO} 2$ concentration at intake manifold to determine the EGR rate [34].

To determine the energy balance terms, the HT from different fluids were measured, thus, the fluid lines were instrumented to measure the flow rate and the temperature. The different sub-systems to measure the HT to the coolant, the engine block oil, the turbocharger oil and the fuel in the return line are presented in Figure 2. The intercooler and EGR cooler heat rejections were obtained from the gas circuit measurements shown in Figure 1. The temperatures of the liquids were measured with RTD because its better accuracy $\left( \pm 0.2^{\circ} \mathrm{C}\right)$ in comparison to the K-type thermocouples $\left( \pm 1.5^{\circ} \mathrm{C}\right)$. This accuracy was a key issue because the temperature variation of the liquids at the exchangers was expected to be small (e.g. cooling water of the fuel return line, at low speed and load, had a variation about $1-2^{\circ} \mathrm{C}$ ). The temperatures of the liquids were controlled by means of PID systems, and valves which regulates the coolant flow in the exchangers.

The acquisition and control of the low frequency signals (mass flows, mean pressures and temperatures except RTD sensors) were carried out with a home developed software called SAMARUC, which also allows visualizing the engine operation parameters, and controlling the operating conditions. The sensors signals were collected and processed in a PXI platform of National instruments. The temperatures measured with the RTD were registered by means of a Datalogger 34972A LXI data acquisition system. The instantaneous in-cylinder pressure signals were acquired by means of a Yokogawa DL708E Oscillographic recorder with 16 A/D converter module. Finally, the control of the Engine Control Unit (ECU) and the acquisition of its variables were done by means of an interface that allows reading and modifying the engine cartography and setting the required operating conditions. 


\section{Global energy balance}

Taking into account all the energy transformations that can take place in a DI Diesel engine, the paths followed by the different energy terms through the engine are presented in the Figure 3. The engine systems are assumed to be delimited by a dashed line which separates the external process, in which the engine is assumed to be a black-box that exchanges energy with the surrounding through the brake power, heat flows and incoming and outgoing enthalpy fluxes from the internal processes such as: HT in the chamber and mechanical losses.

The energy flows entering to the engine are: the sensible enthalpies of air $\dot{m}_{a} h_{a}^{\text {sens }}$ and fuel $\dot{m}_{f} h_{f}^{\text {sens }}$ and the chemical energy of the fuel $\dot{m}_{f} H_{v}$. The main outlet energy flows are the brake power $N_{b}$, the heat flow to the coolant $\dot{Q}_{c o o l}$, the sensible energy of the exhaust gases $\dot{m}_{e x h} h_{e x h}^{\text {sens }}$, the heat flow removed in the oil exchanger $\dot{Q}_{o i l}$, the HT to the turbo oil $\dot{Q}_{t u r b o}$, the heat flow in the intercooler $\dot{Q}_{a}$, the small term corresponding to the heating of the fuel returning to the tank $\dot{Q}_{f}$, the convective and radiative HT to the ambient from the engine parts and sub-systems $\dot{Q}_{\text {ext }}$, the enthalpy flow due to blow-by losses (externally collected) $\dot{m}_{b b} h_{b b}^{\text {sens }}$, and finally, the energy losses due to incomplete combustion $\dot{H}_{i c}$. The electrical system of the engine is connected to an external power supply, with negligible power consumption.

From a thermodynamic point of view, all the energy terms presented in Figure 3 are correct, but for the sake of comprehension, it is interesting to rearrange some of them to perform the detailed analysis of the energy repartition. The description of all the terms and how they are determined in the GEB analysis is the following:

- $\dot{H}_{g}$ : as shown in Equation 1, it is the net flow of sensible enthalpy determined by means of a balance between the incoming and outgoing enthalpy flows at intake (upstream the compressor) and exhaust (after the turbine conditions).

$$
\dot{H}_{g}=\dot{m}_{e x h} h_{\text {exh }}^{\text {sens }}-\dot{m}_{a} h_{a}^{\text {sens }}-\dot{m}_{f} h_{f}^{\text {sens }}
$$

where $\dot{m}_{a}, \dot{m}_{f}$ and $\dot{m}_{e x h}$ are the air, fuel and exhaust mass flow rates measured, and $h_{a}^{\text {sens }}, h_{f}^{\text {sens }}$ and $h_{\text {exh }}^{\text {sens }}$ are the specific sensible enthalpies of air, fuel and exhaust gases, determined from the corresponding specific heats $\left(c_{p, a}\right.$, $c_{p, f}$ and $\left.c_{p, e x h}\right)$ by integration as shown in Equation 4.

$$
\begin{aligned}
h_{a}^{\text {sens }} & =\int_{T_{0}}^{T_{a}} c_{p, a} d T \\
h_{f}^{\text {sens }} & =\int_{T_{0}}^{T_{f}} c_{p, f} d T \\
h_{\text {exh }}^{\text {sens }} & =\int_{T_{0}}^{T_{e x h}} c_{p, e x h} d T
\end{aligned}
$$


where $T_{0}$ is $25^{\circ} \mathrm{C}$ and $T_{a}, T_{f}$ and $T_{e x h}$ are the air, fuel and exhaust gases temperatures at which the enthalpy is computed. Finally, the exhaust mass flow is calculated as presented in Equation 5:

$$
\dot{m}_{e x h}=\dot{m}_{a}+\dot{m}_{f}-\dot{m}_{b b}
$$

being $\dot{m}_{b b}$ the blow-by flow rate.

- $\dot{m}_{f} H_{v}$ : it is the chemical power of the fuel, determined by measuring the fuel mass flow and knowing its heating value $(42.92 \mathrm{MJ} / \mathrm{kg})$.

- $N_{b}$ : it is the brake power that was determined by measuring the engine speed $n$ and torque $M$ in the dynamometer as Equation 6 shows:

$$
N_{b}=2 \pi n M
$$

- $\dot{Q}_{\text {cool }}$ : it is the total HT to the coolant that can be estimated as presented in Equation 7, from the specific heat of the coolant $c_{p, \text { cool }}$, and the measurement of the coolant flow rate $\dot{m}_{\text {cool }}$, and the coolant flow temperature at exchanger inlet $T_{\text {cool, in }}$, and outlet $T_{\text {cool,out }}$.

$$
\dot{Q}_{\text {cool }}=\dot{m}_{\text {cool }} c_{p, \text { cool }}\left(T_{\text {cool }, \text { out }}-T_{\text {cool, in }}\right)
$$

Since the engine coolant refrigerates the engine block as well as the EGR, $\dot{Q}_{\text {cool }}$ includes two heat sources, one regarding the HT to the block and one accounting for the HT in the EGR cooler $\dot{Q}_{E G R}$.

- $\dot{Q}_{E G R}$ : it is the heat losses in the EGR cooler, determined from the EGR mass flow, $\dot{m}_{E G R}$, obtained from the EGR rate (which is determined by the Horiba Mexa 7100 DEGR based on the $\mathrm{CO}_{2}$ compositions measurement), as presented in Equation 8, and measuring the temperature drop in the EGR cooler. The enthalpy difference can be calculated as presented in Equation 9, where $c_{p, E G R}$ is the specific heat of the burned gases.

$$
\begin{gathered}
\dot{m}_{E G R}=\dot{m}_{a}\left(\frac{E G R}{1-E G R}\right) \\
\dot{Q}_{E G R}=\dot{m}_{E G R} c_{p, E G R}\left(T_{E G R, \text { out }}-T_{E G R, \text { in }}\right)
\end{gathered}
$$

- $\dot{Q}_{\text {oil }}$ : it is the heat rejection to the oil in the engine block that was determined with Equation 10, by measuring the water flow rate that refrigerates the oil exchanger $\dot{m}_{w, o i l}$, and the temperatures at the heat exchanger inlet $T_{w, \text { oil,in }}$ and outlet $T_{w, \text { oil,out }}$ 


$$
\dot{Q}_{\text {oil }} \cong \dot{Q}_{w, \text { oil }}=\dot{m}_{w, \text { oil }} c_{p, w, \text { oil }}\left(T_{w, \text { oil out }}-T_{w, \text { oil }, \text { in }}\right)
$$

where $\dot{Q}_{w, o i l}$ is the HT evacuated by the oil exchanger cooling water, and $c_{p, w, o i l}$ is the specific heat of the water.

- $\dot{Q}_{t u r b o}$ : it is the HT rejected in the turbocharger to the oil that was obtained by using an independent conditioning system, in which the turbo oil flow rate $\dot{m}_{\text {oil, },}$ and the temperature at the turbo inlet $T_{\text {oilt,tin }}$ and outlet $T_{\text {oil,t,out }}$ were measured.

$$
\dot{Q}_{\text {turbo }}=\dot{m}_{\text {oil, },} c_{p, o i l, t}\left(T_{\text {oil, }, \text { out }}-T_{\text {oil, t,in }}\right)
$$

were $c_{p, o i l, t}$ is the specific heat of the oil in the turbocharger.

- $\dot{Q}_{a}$ : it is the heat rejection in the intercooler. In the original engine, the intercooler cooling fluid is air, the installation was modified to include a water-air cooler. $\dot{Q}_{a}$ was determined from the air mass flow and its temperature variation.

$$
\dot{Q}_{a}=\dot{m}_{a} c_{p, a}\left(T_{a, o u t}-T_{a, \text { in }}\right)
$$

where $T_{a, \text { in }}$ and $T_{a, \text { out }}$ are the temperatures at inlet and outlet of the intercooler respectively, and $c_{p, a}$ is the specific heat of the air.

- $\dot{Q}_{f}$ : it is the heat loss due to the heating of the returning fuel, which is compressed in the high pressure injection pump from the feeding pressure to the injection pressure. To evacuate this thermal power, the original circuit was modified to control the returning fuel temperature by means of a shell and tube heat exchanger that allowed cooling the fuel returning line to maintain the same temperature as at the high pressure pump inlet. Then, the HT is estimated as presented in Equation 13 by measuring the water flow $\dot{m}_{w, f}$ through the exchanger, and the temperature at inlet $T_{w, f, i n}$ and outlet $T_{w, f, o u t}$ and using the specific heat of the water $c_{p, w, f}$.

$$
\dot{Q}_{f}=\dot{Q}_{w, f}=\dot{m}_{w, f} c_{p, w, f}\left(T_{w, f, o u t}-T_{w, f, i n}\right)
$$

- $\dot{Q}_{\text {ext }}$ : it is the HT to the ambient due to convection and radiation from the engine block, manifolds and the turbocharger walls which is determined in some works by encapsulating the engine. Smith [26] reported a maximum HT values about $10 \%$ of the fuel energy in the case of the engine body, and $5 \%$ in the case of the turbocharger; however, this values where obtained at low engine speed and load where the engine and turbine power are low [35]. The necessity of a special experimental installation to measure $\dot{Q}_{e x t}$ and the fact that $\dot{Q}_{e x t}$ is only important at determined operating conditions (where the experimental uncertainty is also high) leads to 
the decision of not to measure it, but to include it in a miscellanea term $\dot{Q}_{m i s c}$, whose determination is explained later.

- $\dot{H}_{b b}$ : it is the blow-by sensible enthalpy, determined by measuring the blow-by flow mass $\dot{m}_{b b}$ and assuming a blow-by mean temperature similar to the oil temperature in the crank case, to determine its specific enthalpy $h_{b b}^{\text {sens }}$.

$$
\dot{H}_{b b}=\dot{m}_{b b} h_{b b}^{\text {sens }}
$$

- $\dot{H}_{i c}$ : it is the energy losses due to incomplete combustion. It was determined from $H C, C O$ and soot emissions concentrations.

- $\dot{Q}_{m i s c}:$ it is a miscellanea term, defined in Equation 15, which includes some quantities difficult to measure $\left(\dot{Q}_{e x t}\right)$, some terms with small relative weight $\left(\dot{Q}_{t u r b o}, \dot{Q}_{f}, \dot{H}_{b b}\right.$ and $\left.\dot{H}_{i c}\right)$, and finally the experimental unbalance $\left(\dot{Q}_{\text {unbal }}\right)$.

$$
\dot{Q}_{\text {misc }}=\dot{Q}_{\text {ext }}+\dot{Q}_{\text {turbo }}+\dot{Q}_{f}+\dot{H}_{i c}+\dot{H}_{b b}+\dot{Q}_{\text {unbal }}
$$

$\dot{Q}_{e x t}+\dot{Q}_{\text {unbal }}$ is determined by calculating the difference between the rest of the terms involved in the energy balance and the total chemical fuel energy, as presented in Equation 16.

$$
\dot{Q}_{\text {ext }}+\dot{Q}_{\text {unbal }}=\dot{m}_{f} H_{v}-N_{b}-\dot{Q}_{c o o l}-\dot{Q}_{\text {oil }}-\dot{Q}_{a}-\dot{H}_{g}-\dot{Q}_{t u r b o}-\dot{Q}_{f}-\dot{H}_{i c}-\dot{H}_{b b}
$$

- $N_{i}, N_{f r}, N_{a}$ and $N_{p}$ : they are the indicated power $N_{i}$, the friction losses $N_{f r}$, the ancillaries losses $N_{a}$ and the pumping work $N_{p}$. In spite of these terms are not considered in the GEB, their determination and analysis is important to the understanding of some terms such as the brake power or the heat rejection. $N_{i}$ and $N_{p}$ are determined from the $p-V$ diagram integration, while $N_{f r}+N_{a}$ are obtained by subtracting $N_{b}$ to the net indicated power, as presented in Equation 17.

$$
N_{f r}+N_{a}=N_{i}-N_{p}-N_{b}
$$

\section{Experimental results and discussion}

As stated before, the main objective of this work is to analyse the trends of the energy repartition at different operating conditions and parametric variations. Some parametric analysis was carried out varying the variables of interest with a significant influence on thermal management and engine efficiency, i.e: the engine speed and load (engine map), the coolant and oil temperatures, the intake temperature and the SOI. The relative importance of each term is 
analysed in detail.

To ensure a stable thermal behaviour of the engine, stabilization periods between consecutive measurements ranging from 20 to 40 min were required. It was assumed that the thermal stabilization was reached when the variation rate of the temperature of all the liquids (coolant, cooling water and oil) was lower to $1^{\circ} \mathrm{C}$ per minute, being this limit within the accuracy range of the thermocouples. The gas temperatures (intake air and exhaust gases) were also controlled, but the stabilization was faster than in the case of the liquids, thanks to the lower thermal inertia and the higher convective HT between those fluids and the thermocouples and RTDs. The stabilization time is higher in the case of engine heating at low speed and loads because of the lower heat rejection, being necessary a longer stabilization to reach stable temperature in comparison with those at high speed and load conditions, when the fluids were heated faster. In the reference conditions the coolant temperature was set to $85^{\circ} \mathrm{C}$, the oil at $90^{\circ} \mathrm{C}$ and the fresh air at $30^{\circ} \mathrm{C}$ (after the intercooler and before the mixing with the EGR); the rest of parameters were automatically set by the ECU. o ensure repeatability, an active control of key parameters was made; especial attention was paid to the injection setting (injected fuel mass and the SOI) to avoid small variations that could lead to combustion changes, thus affecting the repeatability and the conclusions regarding the parameter effects.

All the measured points are summarized in Table 3. Although a complete measurement matrix was available for the parametric studies, for the sake of brevity only the results corresponding to 2000 and $4000 \mathrm{rpm}$ and $25 \%$ and $50 \%$ load are presented. This operating points were selected, on the one hand, because these engine speeds allows assessing the effect of reducing the HT time one half, and on the other hand, the same trends were observed in all the operating points measured in this work. Three repetitions of each operating point were measured and their results averaged to obtain the results that are discussed in the next sections. Both absolute and relative energy terms are going to be presented. The relative energy terms use the fuel energy $\left(\% \dot{m}_{f} H_{v}\right)$ as reference to analyse the effect on the consumption and energy repartition. Only relative variations higher than $0.5 \%$ are highlighted.

\subsection{Engine speed and load variation}

The main energy terms involved in the GEB are presented in Equation 18. To assess the importance of each term in different regions of the engine map, firstly, a complete speed and load sweep was performed, being the measurement conditions those presented in Table 3.

$$
m_{f} H_{v}=\dot{Q}_{c o o l}+\dot{Q}_{E G R}+\dot{Q}_{o i l}+\dot{H}_{g}+\dot{Q}_{a}+\dot{Q}_{m i s c}
$$

To analyse the influence of each energy term in Equation 18, their relative weight in terms of the fuel energy is presented from Figure 4 to 13, where also the maps with the indicated, brake and mechanical efficiencies have been included to help the explanation of the observed trends. The following conclusions can be highlighted: 
- Regarding $\dot{Q}_{\text {cool }}$, Figure 4 shows that there is a clear trend to increase its relative weight when the engine speed is reduced, ranging from about $16 \%$ at high speed and load to $26 \%$ at low speed and load. This can be explained taking into account that the lower the engine speed is, the higher the residence time of the fluids in the engine is, in particular, the gases in the combustion chamber and exhaust ports where most of the HT takes place. Thus, the reduction of the HT coefficient at low speed due to the lower gas velocities is not enough to compensate this increment of time. On the other hand, the effect of the load on $\dot{Q}_{c o o l}$ does not show a clear trend up to mid engine speed, while in the range from 2000 to $4000 \mathrm{rpm}$, the higher the load is, the lower the HT is. This different behaviour is due to the different engine setting regarding air management and injection: on the one hand at low speed and load the EGR is higher, on the other hand the injection settings (number of injections and phasing) lead to different combustion process.

- No EGR strategy was used at high load and speed above $3500 \mathrm{rpm}$, therefore, at these operating conditions no EGR refrigeration was required. As shown in Figure 5, the maximum HT rejection in the EGR cooler is lower than 5\% in the complete engine map. This value is reached at $2500 \mathrm{rpm}$ and low load, where the EGR rate is about $30 \%$.

- The HT to the oil is shown in Figure 6. It can be seen a clear effect of the load, being minimum near the full load and presenting a slight trend to diminish when the engine speed increases. On the one hand, this trend is due to the relative effect of the mechanical losses, which are lower at high load as presented in Figure 7. On the other hand, the effect of the HT in the chamber (higher at low speed and load and lower at high speed and load) partially compensates the friction effect, thus leading to the global trend observed for $\dot{Q}_{o i l}$, with a low variation at different engine speed.

- In general, $\dot{H}_{g}$ (Figure 8) depends on both the engine speed and load, thus the higher the load and speed are, the higher the relative weight of the exhaust gases energy is. This behaviour is consequence, on the one hand, of the trends observed in $\dot{Q}_{c o o l}$ and $\dot{Q}_{o i l}$ : since at high speed and load the HT is lower, most of the coolant and oil heat rejection reduction is evacuated mainly as sensible enthalpy at exhaust. On the other hand, the effect of the EGR shown at Figure 5 is more important at mid speed and low load, thus producing a reduction of the $\dot{H}_{g}$ when comparing with mid speed and high load. This is mainly explained by the lower exhaust mass flow (because the fresh air per cycle is lower due to the EGR) and the lower fuel to air ratio, which leads to lower exhaust temperatures.

- The heat losses in the intercooler (Figure 9) are higher at high speed and load operating conditions due to the effect of air compression in the turbocharger. Thus, at higher speed and load, more energy is available to be used in the turbine and hence a higher compression work is done in the compressor, leading to higher air temperature and higher relative cooling demand in the intercooler.

- The behaviour of the indicated efficiency $\eta_{i}$ shown in Figure 10 is determined by the combustion development 
and the HT in the combustion chamber (which also depends on the combustion process), and thus, it depends on huge number of variables. There is a global trend to increase $\eta_{i}$ when the engine speed increases that can be justified because of the lower HT to the chamber, as previously shown. This HT reduction at high load is probably compensated with the increase of the combustion duration due to the higher fuel mass injected. The change of the number of injection pulses and the effect of EGR are also variables that contribute to the slightly effect of the load.

- The behaviour of the brake efficiency $\eta_{b}$ observed in Figure 11 can be explained from $\eta_{i}$ (Figure 10) and the mechanical efficiency $\eta_{m}$ (Figure 12): at high speed, $\eta_{i}$ trends to increase while the friction and mechanical losses are higher, thus the maximum $\eta_{b}$ is reached at mid speed. On the other hand, $\eta_{i}$ shows a poor effect with the load while $\eta_{m}$ reaches its maximum at high load, therefore the maximum $\eta_{b}$ is reached near the full load operation.

- Finally, as shown in Figure 13, the lower the speed and load are, the higher the relative weight of $\dot{Q}_{\text {misc }}$ is. This trend can be explained because of two main reasons: On the one hand, at low speed and load, the relative weight of the HT to the ambient is higher because the external wall temperature of the engine is mainly dependent on coolant temperature, which does not change dramatically with the engine load and speed, contrary to the fuel mass. On the other hand the experimental error increases due to the smaller power of all the experimental terms measured, thus, at these conditions, the temperature differences and flow rates are smaller and the relative errors tends to increase.

Taking into account the results of the engine maps, it is possible to conclude that the most important energy terms are $\eta_{b}\left(26-38 \% m_{f} H_{v}\right), \dot{H}_{g}\left(15-36 \% m_{f} H_{v}\right)$ and $\dot{Q}_{c o o l}\left(17-26 \% m_{f} H_{v}\right)$. Though less important, $\dot{Q}_{o i l}$ (lower than 10 $\% m_{f} H_{v}$ ) and $\dot{Q}_{a}$ (lower than $8 \% m_{f} H_{v}$ ) also had an important weight at determined operating conditions. $\dot{Q}_{m i s c}$ which includes the HT to the ambient $\left(\dot{Q}_{e x t}\right)$, some terms with a small relative weight $\left(\dot{Q}_{t u r b o}, \dot{Q}_{f}, \dot{Q}_{u n}\right.$ and $\dot{H}_{b b}$, all of them lower than $1 \% m_{f} H_{v}$ ), and finally the experimental unbalance $\dot{Q}_{u n b a l}$ which is only important at low speed and load.

\subsection{Fluids temperature and SOI variation}

To assess the energy repartition when varying some other parameters affecting the most important energy terms, 3 parametric studies were carried out: coolant temperature, which mainly affects the engine HT, the intake air temperature which mainly affects HT and combustion development, and finally the SOI, which has a direct effect on the indicated cycle and exhaust enthalpy.

In order to reduce the uncertainties regarding the trapped mass, the intake temperature and the charge composition, the following parametric studies were carried out with no EGR (its effect on the GEB was analysed in the previous section). Taking into account that the coolant, oil and intake air temperature variation ranges depend on the operating 
point, the normalization presented in Equation 19 was performed, taking as reference the variation range $\left(\Delta P_{r e f}\right)$ at $2000 \mathrm{rpm}$.

$$
\Delta \dot{Q}_{i, N}=\Delta \dot{Q}_{i} \times \frac{\Delta P_{r e f}}{\Delta P}
$$

Being $\Delta \dot{Q}_{i, N}$ the normalized energy variation, the $i$ index the energy term considered, and $\Delta P$ the variation range of the respective parameter (coolant or intake temperature). If the values of determined study at 2000 and $4000 \mathrm{rpm}$ are similar in the Table 4, it must be concluded that there is no speed effect for the same parameter variation. The normalization procedure is not applied in the SOI variation study, since the range is the same $\left( \pm 13^{\circ}\right)$ in all the analysed operating conditions. The GEB of each parametric study is shown in Figure 14 to Figure 16.

\subsubsection{Coolant temperature variation}

This parametric study was carried out maintaining constant the engine torque when the coolant temperature was changed. The coolant temperature was set to $65^{\circ} \mathrm{C}, 75^{\circ} \mathrm{C}$ and $85^{\circ} \mathrm{C}$. Due to the engine configuration (the original oil cooler was used), the flexibility of the oil cooling is limited because its temperature is highly dependent on the coolant temperature. Hence, the oil temperature changes about the half of the coolant temperature variation (when the coolant temperature ranges from $65^{\circ} \mathrm{C}$ to $85^{\circ} \mathrm{C}$, the oil temperature ranges from $90^{\circ} \mathrm{C}$ to $100^{\circ} \mathrm{C}$ ). For the sake of engine security, low temperatures were omitted at $4000 \mathrm{rpm}$ to avoid increasing the engine friction. Thus, the coolant temperature was varied between $75^{\circ} \mathrm{C}$ and $85^{\circ} \mathrm{C}$ at this operating condition. The information regarding the experimental set is presented in Table $3 \mathrm{~b}$.

Figure 14 shows the results of coolant temperature variation at 2000 and $4000 \mathrm{rpm}$ at medium load. It is possible to see that the effect of coolant temperature variations on $N_{b}$ is small in both operating conditions; in fact, the brake efficiency variation is lower than $0.5 \%$ in all the operating condition analysed (from 1000 to $4000 \mathrm{rpm}$ and from 25 to $75 \%$ load). These results are in good agreement with that reported by Torregrosa et al. [30] and can be justify as follows.

First, increasing the coolant and oil temperatures has a direct impact on wall temperatures, which leads to a diminution in the temperature difference between the gas in the chamber and the walls, resulting in a reduction between 1.6 at $4000 \mathrm{rpm}$ and 3.3\% at $2000 \mathrm{rpm}$ in $\dot{Q}_{\text {cool }}$. Simultaneously, $\dot{Q}_{\text {oil }}$ increases about $1 \%$ due to the reduction of the temperature difference between the oil and the coolant, owing to the lower increment of the oil temperature (half of the coolant increment) and hence the reduction of the HT from oil to coolant in the block, which leads to a higher heat rejection in the oil heat exchanger. The decrease of HT (considering both coolant and oil) is more noticeable at $2000 \mathrm{rpm}$ as can be seen in Figure 14, because the coolant and oil variation is higher. If the normalized variations are considered (see Table 4) the effect is similar (slightly lower at $4000 \mathrm{rpm}$ ). On the other hand, the increase in the engine walls temperature leads to an increase in $\dot{Q}_{m i s c}$ between 0.8 and $1.5 \%$, mainly due to the higher HT to the ambient. 
Also in this case the normalized effect is similar at 2000 and $4000 \mathrm{rpm}$.

The exhaust gases sensible enthalpy increases about $0.5 \%$ at $2000 \mathrm{rpm}$ and $0.4 \%$ at $4000 \mathrm{rpm}$, thus showing that part of the heat rejection reduction is lost with the exhaust gases. Although the net benefit of the $\dot{Q}_{\text {cool }}+\dot{Q}_{\text {oil }}$ reduction is not directly transferred to the $\eta_{b}$, the increase of the exhaust enthalpy is interesting for energy recovery applications such as a bottoming Rankine cycle [36], thus additional benefits can be obtained.

The normalized effects shown in Table 4 confirms that for a comparable coolant temperature variation, the engine speed has not a remarkable effect on the sensitivity of the different energy terms, thus $\Delta \dot{Q}_{c o o l, N}, \Delta \dot{Q}_{o i l, N}$ and $\Delta \dot{Q}_{m i s c, N}$ are $-3.3,1$ and $1.5 \%$ respectively for a variation of $20^{\circ} \mathrm{C}$ at both engine speeds. Table 4 also shows the effect of the coolant temperature increase on $\Delta \eta_{i, N}$ and $\Delta\left(N_{a}+N_{f r}\right)_{N}$, in both cases the observed effects barely depends on the engine speed. The variations about $-0.4 \%$ in $\Delta \eta_{i, N}$ and $-0.3 \%$ in $\Delta\left(N_{a}+N_{f r}\right)_{N}$ are due to the slight fuel mass variation necessary to maintain the same torque.

\subsubsection{Intake air temperature variation}

The study was performed maintaining constant the air and fuel masses when the intake temperature was changed. The increase in the inlet temperature reduces the air density, therefore the air flow mass was adjusted by regulating the inlet pressure to maintain the fuel to air ratio. The first measurement was obtained by setting the nominal air temperature $\left(30^{\circ} \mathrm{C}\right)$. Then, the air temperature was increased by switching off the intercooler, thus reaching the maximum intake temperature depending on the compression ratio at each operating point. Subsequently, the intercooler was fully opened, reaching the minimum possible air temperature (slightly below the nominal value). The experimental conditions are shown in Table $3 \mathrm{c}$. It is interesting to remark that, when the intercooler was fully closed the maximum temperature reached depend on the operating point, whilst when it was fully opened, the minimum temperature was limited by the cooling water supply. Since both, the minimum and the maximum temperatures are not the same at different operating conditions, the results are normalized as described in section 4.2 .

It is possible to see in the Figure 15 that the intake air temperature increment reduces $\eta_{b}$ in $0.9 \%$ at $2000 \mathrm{rpm}$ and $1.3 \%$ at $4000 \mathrm{rpm}$. When the normalized values presented in Table 4 are compared, it is observed that the benefit of cooling the air is more important at $2000 \mathrm{rpm}$, where $\Delta \eta_{b, N}$ improvement is almost two times higher at $2000 \mathrm{rpm}$. The reduction in $\Delta \eta_{b, N}$ is explained by the reduction of $\Delta \eta_{i, N}$ in almost the same extent. As expected, the highest effect of the intake temperature on the GEB is observed in the HT to the intercooler, where the heat rejection lies between $2.5 \%$ at $2000 \mathrm{rpm}$ and $7.3 \%$ at $4000 \mathrm{rpm}\left(2.5 \%\right.$ and $3 \%$ each $35^{\circ} \mathrm{C}$ respectively).

The higher intake temperature results in an increase in the HT from the chamber to the walls, due to the higher gas mean temperature, and hence, the increase of the temperature difference between gas and walls. The absolute variation 
is higher at high engine speed, due to the higher inlet temperature variation; however, in relative terms (Table 4) the effect is slightly higher at low speed: $\Delta \dot{Q}_{c o o l, N}$ increases $3 \%$ and $2.4 \%$ each $35^{\circ} \mathrm{C}$ at 2000 and $4000 \mathrm{rpm}$ respectively and $\Delta \dot{Q}_{o i l, N}$ increases $0.5 \%$ and $0.3 \%$ each $35^{\circ} \mathrm{C}$ at 2000 and $4000 \mathrm{rpm}$ respectively. On the other hand, the results observed for $\Delta \eta_{b, N}$ and $\Delta \dot{H}_{g, N}$ confirms that the use of the intercooler is more beneficial at $2000 \mathrm{rpm}$ because cooling the intake air lies in more brake work, while at $4000 \mathrm{rpm}$ part of the potential benefit results in more exhaust gases energy.

\subsubsection{SOI variation}

This parametric study was performed maintaining constant the air and fuel masses and varying the SOI with respect to the nominal value, the experimental settings are summarized in Table $3 \mathrm{~d}$. Since the energy terms behaviour by advancing or delaying the SOI were considerably different, the analysis was perform separately.

Nowadays, the engine injection settings are mainly optimized to achieve a combustion that comply with the emissions regulations, thus the nominal SOI is not the optimum in terms of $\eta_{b}$, as can be seen in Figure 16. Thus, advancing the SOI about $13^{\circ}$ produces an $\eta_{b}$ increment of $0.7 \%$ at $2000 \mathrm{rpm}$ and $1.4 \%$ at $4000 \mathrm{rpm}$. As can be seen, the effect of the SOI is higher when it is delayed $13^{\circ}: \eta_{b}$ diminishes $5.3 \%$ at $2000 \mathrm{rpm}$ and $7.7 \%$ at $4000 \mathrm{rpm}$, thus showing an engine response which is clearly non-linear. It is interesting to see that advancing the SOI increases the brake efficiency in spite of the friction and chamber HT augmentation, as shown in Figure 16 and Table 4. Thus, it can be said that the benefits of combustion centring on indicated efficiency ( $1.4 \%$ at $2000 \mathrm{rpm}$ and $1.6 \%$ at $4000 \mathrm{rpm}$.) is higher than the worsening of the two stated terms. The increase of $N_{f r}+N_{a}$ at advancing the SOI is due to a higher in-cylinder pressure increment, since the friction in the piston (about 50\% of $N_{f r}+N_{a}$ ) is highly dependent on the in-cylinder pressure [37].

Regarding the heat rejection, there is a global trend to increase HT to the coolant when the combustion is both advanced or delayed. In the first case, it is explained because of the effect of the higher in-cylinder temperature, as can be seen in Figure 17. In spite of delaying the SOI results in lower in-cylinder temperature, which decrease the chamber HT, it was observed that the temperature reached at exhaust valve opening (EVO) is higher, thus increasing the HT to the ports. This HT does not have a direct effect on engine performance; however, the results indicates that the increase in the HT to the ports is higher than the reduction of the chamber HT, therefore an increment about $2 \%$ in $\dot{Q}_{\text {cool }}$ is observed.

In the case of advancing the SOI, the lower temperature at EVO leads to a reduction in $\dot{H}_{g}$ of $2.5 \%$ at $2000 \mathrm{rpm}$ and $2 \%$ at $4000 \mathrm{rpm}$. On the contrary, the higher temperature at EVO in the case of delaying the SOI, results in an increase of $\dot{H}_{g}$ between $3 \%$ and $6 \%$, being more important at $4000 \mathrm{rpm}$ because at these conditions the combustion is longer than at $2000 \mathrm{rpm}$ and the EVO becomes a limitation to complete the combustion process. In this case, the global correlation between $\dot{H}_{g}$ and $N_{b}$ can be easily justified considering that the increase of $\dot{H}_{g}$ means that the energy 
was not well used to produce mechanical work in the expansion stroke.

\section{Conclusions}

A detailed experimental energy balance along with a comprehensive analysis regarding the paths followed by the energy has been presented in this work. The main objective was the identification of the most important energy terms, aimed at the assessing of the most influential parameters, and the impact of some parametric variation in the engine performance.

First, an analysis of the complete engine map allowed determining the variation range of the most important energy terms with the speed and load: the brake efficiency ranges between $30 \%$ and $38 \%$, the HT to the coolant around $20 \%$ in the complete engine map and the net flow of sensible enthalpy ranges between $18 \%$ and $34 \%$. With a lower importance, the HT to the oil varies between $4 \%$ and $10 \%$, the heat rejection in the intercooler lies between $1 \%$ and $7 \%$ and the miscellaneous term between $2 \%$ and $15 \%$. Once the engine map is analysed, some parametric studies on the coolant temperature, intake temperature and SOI were performed to evaluate the GEB behaviour by changing the nominal operating settings:

- The variation of coolant temperature shows an almost negligible effect on the engine efficiency (lower than $0.5 \%$ ). Nevertheless, some important findings should be underlined: when colder coolant temperature is used, the HT from the in-cylinder gas to the coolant is increased, whilst the HT to the oil and to the ambient is decreased. Regarding efficiency, no clear benefit of changing the coolant temperature in the operating ranges was observed; however, the reduction of the HT to the coolant yields to more available energy at exhaust gas that could be used in recovery energy processes such as bottoming Rankine cycles. It is interesting to highlight that the relative variation of the energy terms is the same for both engine speeds analysed.

- The variation of the intake air temperature results in higher effects on the engine performance compared with those achieved by coolant temperature variations. When the air was cooled $35^{\circ} \mathrm{C}$, an increase in the brake efficiency about $1 \%$ was observed, this behaviour is mainly due to the reduction of the chamber HT. The benefits are higher at $2000 \mathrm{rpm}$, where the exhaust gas losses are lower than in the case of $4000 \mathrm{rpm}$.

- The SOI variation was the parameter that presented the greatest influence on the engine efficiency, since it directly changes the combustion phasing and therefore the indicated cycle. The slight improvement by advancing the SOI with respect to the nominal SOI is explained by the indicated efficiency improvement, limited by the engine calibration, which is optimized to reduce emissions. Although advancing the SOI had a negative effect on friction and HT, their effect was lower than the benefit of the combustion centring, in which an improvement 
about $1.5 \%$ was observed. Retarding the SOI around $13^{\circ}$ worsens the engine performance, reducing the brake efficiency around $6 \%$, and increasing the HT losses and the exhaust energy.

Finally, it can be concluded that the experimental tool presented in this work allows performing detailed evaluation and analysis of the engine energy outputs, thus providing useful information regarding possible optimization paths.

\section{Acknowledgments}

The support of the Spanish Ministry of Economy and Competitiveness (TRA2013-41348-R) is greatly acknowledged. 


\section{References}

[1] B. Mohan, W. Yang, S. K. Chou, Fuel injection strategies for performance improvement and emissions reduction in compression ignition engines-A review, Renewable and Sustainable Energy Reviews 28 (2013) 664-676 doi:10.1016/j.rser.2013.08.051.

[2] A. K. Agarwal, D. K. Srivastava, A. Dhar, R. K. Maurya, P. C. Shukla, A. P. Singh, Effect of fuel injection timing and pressure on combustion, emissions and performance characteristics of a single cylinder diesel engine, Fuel 111 (2013) 374-383 doi:10.1016/j.fuel.2013.03.016.

[3] S. D. Hiwase, S. Moorthy, H. Prasad, M. Dumpa, R. M. Metkar, Multidimensional Modeling of Direct Injection Diesel Engine with Split Multiple Stage Fuel Injections, Procedia Engineering 51 (2013) 670-675 doi:10.1016/j.proeng.2013.01.095.

[4] M. Canakci, Combustion characteristics of a DI-HCCI gasoline engine running at different boost pressures, Fuel 96 (2012) 546-555 doi:10.1016/j.fuel.2012.01.042.

[5] F. Perini, P. C. Miles, R. D. Reitz, A comprehensive modeling study of in-cylinder fluid flows in a high-swirl, light-duty optical diesel engine, Computers \& Fluids 105 (2014) 113-124 doi:10.1016/j.compfluid.2014.09.011.

[6] S. Wei, F. Wang, X. Leng, X. Liu, K. Ji, Numerical analysis on the effect of swirl ratios on swirl chamber combustion system of DI diesel engines, Energy Conversion and Management 75 (2013) 184-190 doi:10.1016/j.enconman.2013.05.044.

[7] J. Benajes, R. Novella, D. DeLima, P. Tribotté, N. Quechon, P. Obernesser, V. Dugue, Analysis ofthe combustion process, pollutant emissions and efficiency of an innovative 2-stroke HSDI engine designed for automotive applications, Applied Thermal Engineering 58 (1-2) (2013) 181-193 doi:10.1016/j.applthermaleng.2013.03.050.

[8] M. Pan, G. Shu, H. Wei, T. Zhu, Y. Liang, C. Liu, Effects of EGR, compression ratio and boost pressure on cyclic variation of PFI gasoline engine at WOT operation, Applied Thermal Engineering 64 (1-2) (2014) 491-498 doi:10.1016/j.applthermaleng.2013.11.013.

[9] G. Fontana, E. Galloni, Experimental analysis of a spark-ignition engine using exhaust gas recycle at WOT operation, Applied Energy 87 (7) (2010) 2187-2193 doi:10.1016/j.apenergy.2009.11.022.

[10] S. Verhelst, J. Demuynck, R. Sierens, P. Huyskens, Impact of variable valve timing on power, emissions and backfire of a bi-fuel hydrogen/gasoline engine, International Journal of Hydrogen Energy 35 (9) (2010) 4399-4408 doi:10.1016/j.ijhydene.2010.02.022.

[11] G. Fontana, E. Galloni, Variable valve timing for fuel economy improvement in a small spark-ignition engine, Applied Energy 86 (1) (2009) 96-105 doi:10.1016/j.apenergy.2008.04.009.

[12] C. Guardiola, J. López, J. Martín, D. García-Sarmiento, Semiempirical in-cylinder pressure based model for NOX prediction oriented to control applications, Applied Thermal Engineering 31 (12) (2011) 3275-3286 doi:10.1016/j.applthermaleng.2011.05.048.

[13] T. Sandalcı, Y. Karagöz, Experimental investigation of the combustion characteristics, emissions and performance of hydrogen port fuel injection in a diesel engine, International Journal of Hydrogen Energy (2014) 1-10 doi:10.1016/j.ijhydene.2014.09.044.

[14] K. A. Sorate, P. V. Bhale, Biodiesel properties and automotive system compatibility issues, Renewable and Sustainable Energy Reviews 41 (2015) 777-798 doi:10.1016/j.rser.2014.08.079.

[15] J. Heywood, Internal Combustion Engines Fundamentals, McGraw-Hill, New York, 1988.

[16] V. Bermúdez, J. M. Luján, P. Piqueras, D. Campos, Pollutants emission and particle behavior in a pre-turbo aftertreatment light-duty diesel engine, Energy 66 (2014) 509-522 doi:10.1016/j.energy.2014.02.004.

[17] Regulation (EU) No 333/2014 of the European Parliament and of the Council of 11 March 2014 amending Regulation (EC) No $443 / 2009$ to define the modalities for reaching the 2020 target to reduce CO2 emissions from new passenger cars, Official Journal of the European Union L 103 Vol 57 15-21

[18] R. D. Burke, C. J. Brace, J. G. Hawley, I. Pegg, Review of the systems analysis of interactions between the thermal, lubricant, and combustion processes of diesel engines, Journal of Automobile Engineering doi:10.1243/09544070JAUTO1301.

[19] F. Caresana, M. Bilancia, C. Bartolini, Numerical method for assessing the potential of smart engine thermal management: Application to a medium-upper segment passenger car, Applied Thermal Engineering 31 (16) (2011) 3559-3568 doi:10.1016/j.applthermaleng.2011.07.017.

[20] P. Dimopoulos, C. Bach, P. Soltic, K. Boulouchos, Hydrogen-natural gas blends fuelling passenger car engines: Combustion, emissions and well-to-wheels assessment, International Journal of Hydrogen Energy 33 (23) (2008) 7224-7236 doi:10.1016/j.ijhydene.2008.07.012.

[21] A. Sanli, A. N. Ozsezen, I. Kilicaslan, M. Canakci, The influence of engine speed and load on the heat transfer between gases and 
in-cylinder walls at fired and motored conditions of an IDI diesel engine, Applied Thermal Engineering 28 (11-12) (2008) 1395-1404 doi:10.1016/j.applthermaleng.2007.10.005.

[22] I. Taymaz, An experimental study of energy balance in low heat rejection diesel engine, Energy 31 (2-3) (2006) 364-371 doi:10.1016/j.energy.2005.02.004

[23] V. Macián, B. Tormos, V. Bermúdez, L. Ramírez, Assessment of the effect of low viscosity oils usage on a light duty diesel engine fuel consumption in stationary and transient conditions, Tribology International 79 (2014) 132-139 doi:10.1016/j.triboint.2014.06.003.

[24] U. Morawitz, J. Mehring, L. Schramm, Benefits of Thermal Spray Coatings in Internal Combustion Engines, with Specific View on Friction Reduction and Thermal Management, SAE Technical paper 2013-01-0292 doi:10.4271/2013-01-0292.

[25] J.R.Serrano, P.Olmeda, A.Tiseira, L.M.García-Cuevas, A.Lefebvre, Theoretical and experimental study of mechanical losses in automotive turbochargers, Energy 55 (2013) 888-898 doi:10.1016/j.energy.2013.04.042.

[26] L. A. Smith, W. H. Preston, G. Dowd, O. Taylor, K. M. Wilkinson, Application of a First Law Heat Balance Method to a Turbocharged Automotive Diesel Engine, SAE Technical paper 2009-01-0244 doi:10.4271/2009-01-2744.

[27] X. Tauzia, A. Maiboom, Experimental study of an automotive Diesel engine efficiency when running under stoichiometric conditions, Applied Energy 105 (2013) 116-124 doi:10.1016/j.apenergy.2012.12.034.

[28] E. Ajav, B. Singh, T. Bhattacharya, Thermal balance of a single cylinder diesel engine operating on alternative fuels, Energy Conversion and Management 41 (14) (2000) 1533-1541. doi:10.1016/S0196-8904(99)00175-2.

[29] M. Abedin, H. Masjuki, M. Kalam, A. Sanjid, S. A. Rahman, B. Masum, Energy balance of internal combustion engines using alternative fuels, Renewable and Sustainable Energy Reviews 26 (2013) 20-33 doi:10.1016/j.rser.2013.05.049.

[30] A. Torregrosa, P. Olmeda, J. Martín, B. Degraeuwe, Experiments on the influence of inlet charge and coolant temperature on performance and emissions of a DI Diesel engine, Experimental Thermal and Fluid Science 30 (7) (2006) 633-641 doi:10.1016/j.expthermflusci.2006.01.002.

[31] F. Payri, J. Luján, J. Martín, A. Abbad, Digital signal processing of in-cylinder pressure for combustion diagnosis of internal combustion engines, Mechanical Systems and Signal Processing 24 (6) (2010) 1767-1784 doi:10.1016/j.ymssp.2009.12.011.

[32] J. Tichý, G. Gautschi, Elektrische Meßtechnik, Springer, Berlin, 1980.

[33] J. Benajes, P. Olmeda, J. Martín, R. Carreño, A new methodology for uncertainties characterization in combustion diagnosis and thermodynamic modelling, Applied Thermal Engineering 71 (2014) 389-399 doi:10.1016/j.applthermaleng.2014.07.010.

[34] V. Bermúdez, J. M. Lujan, B. Pla, W. G. Linares, Effects of low pressure exhaust gas recirculation on regulated and unregulated gaseous emissions during NEDC in a light-duty diesel engine, Energy 36 (9) (2011) 5655-5665. doi:10.1016/j.energy.2011.06.061.

[35] F. Payri, P. Olmeda, F. J. Arnau, A. Dombrovsky, L. Smith, External heat losses in small turbochargers: Model and experiments, Energy 71 (2014) 534-546 doi:10.1016/j.energy.2014.04.096.

[36] V. Macián, J. Serrano, V. Dolz, J. Sánchez, Methodology to design a bottoming Rankine cycle, as a waste energy recovering system in vehicles. Study in a HDD engine, Applied Energy 104 (2013) 758-771 doi:10.1016/j.apenergy.2012.11.075.

[37] R. Stanley, D. Taraza, N. Henein, A Simplified Friction Model of the Piston Ring Assembly, SAE Technical Paper 1999-01-0974 doi:10.4271/1999-01-0974. 


\section{Figures}

Figure 1. Scheme of the gases circuit

Figure 2. Scheme of the liquids (coolant, water and oil) circuit

Figure 3. Scheme of the energy flows considered

Figure 4. Heat transfer to the coolant excluding EGR $\left(\dot{Q}_{c o o l}\right)\left[\% \dot{m}_{f} H_{v}\right]$

Figure 5. Heat transfer to the EGR cooling water $\left(\dot{Q}_{E G R}\right)\left[\% \dot{m}_{f} H_{v}\right]$

Figure 6. Heat transfer to the oil $\left(\dot{Q}_{o i l}\right)\left[\%_{m_{f}} H_{v}\right]$

Figure 7. Ancillaries and friction $\left(N_{a}+N_{f r}\right)\left[\% \dot{m}_{f} H_{v}\right]$

Figure 8. Exhaust gases sensible enthalpy $\left(\dot{H}_{g}\right)\left[\% \dot{m}_{f} H_{v}\right]$

Figure 9. Heat transfer in the intercooler $\left(\dot{Q}_{a}\right)\left[\% \dot{m}_{f} H_{v}\right]$

Figure 10. Indicated efficiency $\left(\eta_{i}\right)\left[\% \dot{m}_{f} H_{v}\right]$

Figure 11. Brake efficiency $\left(\eta_{b}\right)\left[\% \dot{m}_{f} H_{v}\right]$

Figure 12. Mechanical efficiency $\left(\frac{N_{b}}{N_{i}} \times 100\right)$

Figure 13. Miscellaneous term $\left(\dot{Q}_{m i s c}\right)\left[\% \dot{m}_{f} H_{v}\right]$

Figure 14. GEB for the coolant temperature variation in a set of 50\% load operating points, left $2000 \mathrm{rpm}$, right $4000 \mathrm{rpm}$

Figure 15. GEB for the intake temperature variation in a set of $25 \%$ load operating points, left $2000 \mathrm{rpm}$, right $4000 \mathrm{rpm}$

Figure 16. GEB for the SOI variation in a set of 50\% load operating points, left $2000 \mathrm{rpm}$, right $4000 \mathrm{rpm}$

Figure 17. Gas Temperature due to a SOI variation of $\pm 13^{\circ}$ at $2000 \mathrm{rpm}$ and $50 \% \mathrm{Load}$ 


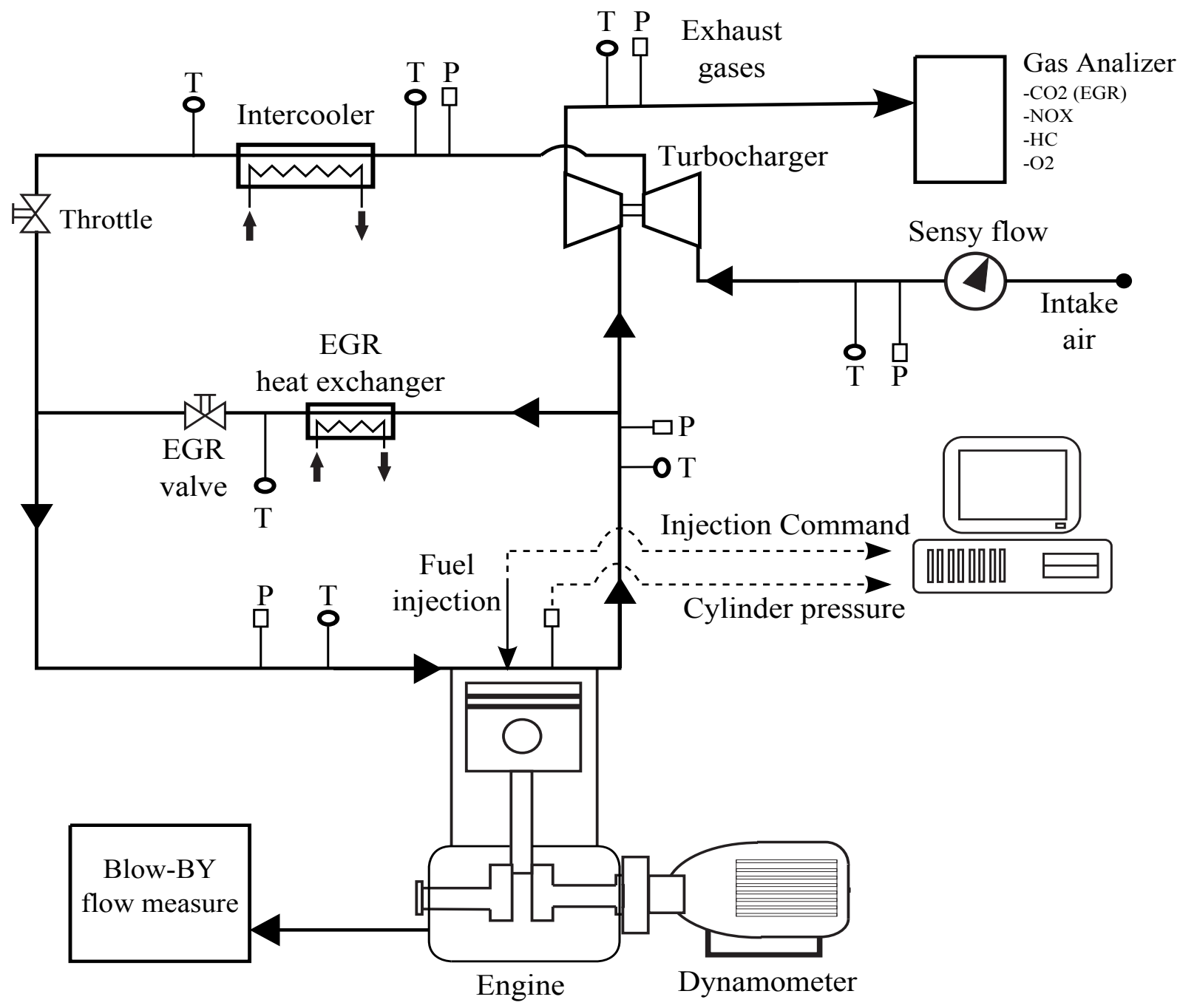

Figure 1: Scheme of the gases circuit 


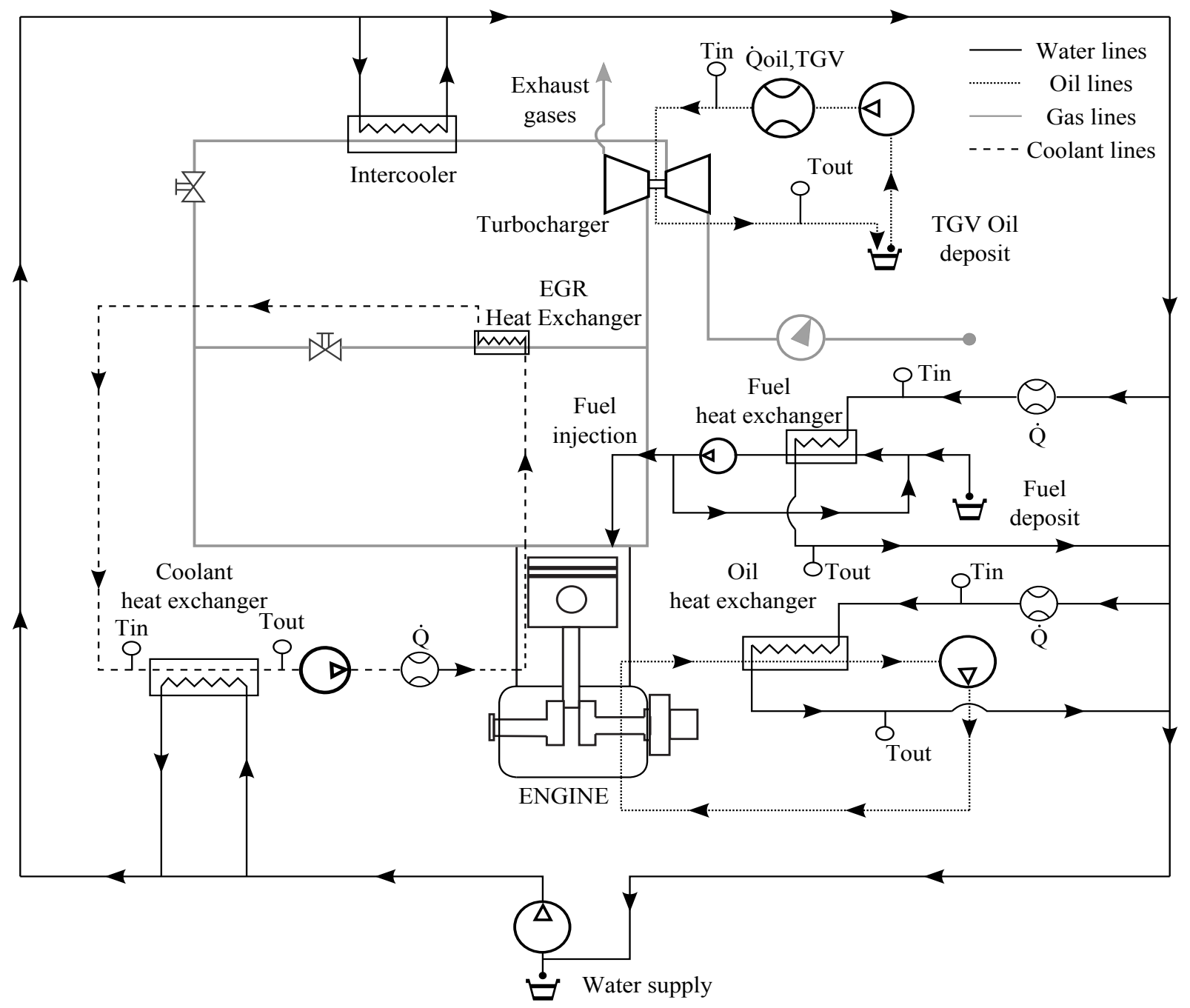

Figure 2: Scheme of the liquids (coolant, water and oil) circuit 


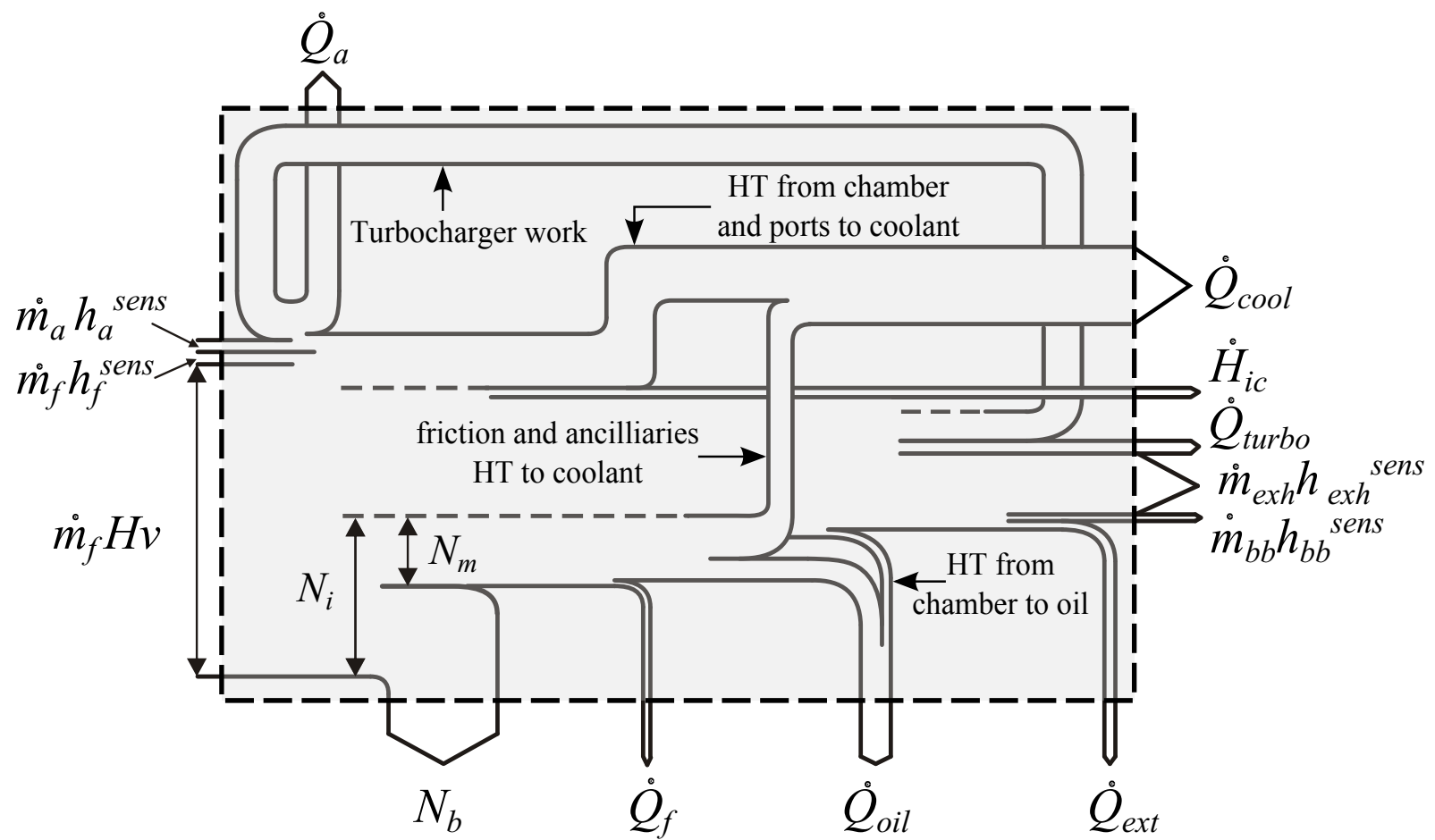

Figure 3: Scheme of the energy flows considered 


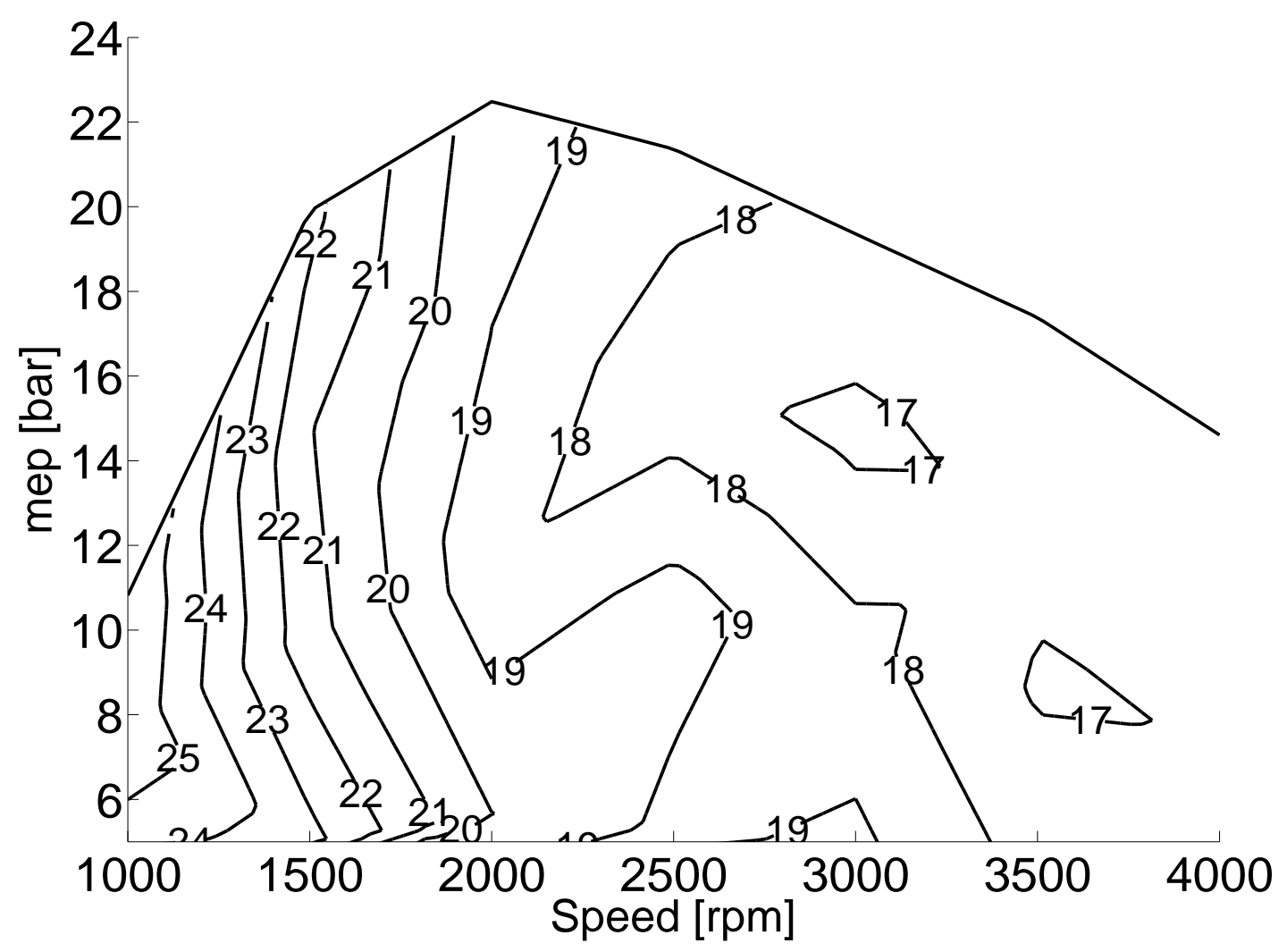

Figure 4: Heat transfer to the coolant excluding EGR $\left(\dot{Q}_{c o o l}\right)\left[\% \dot{m}_{f} H_{v}\right]$ 


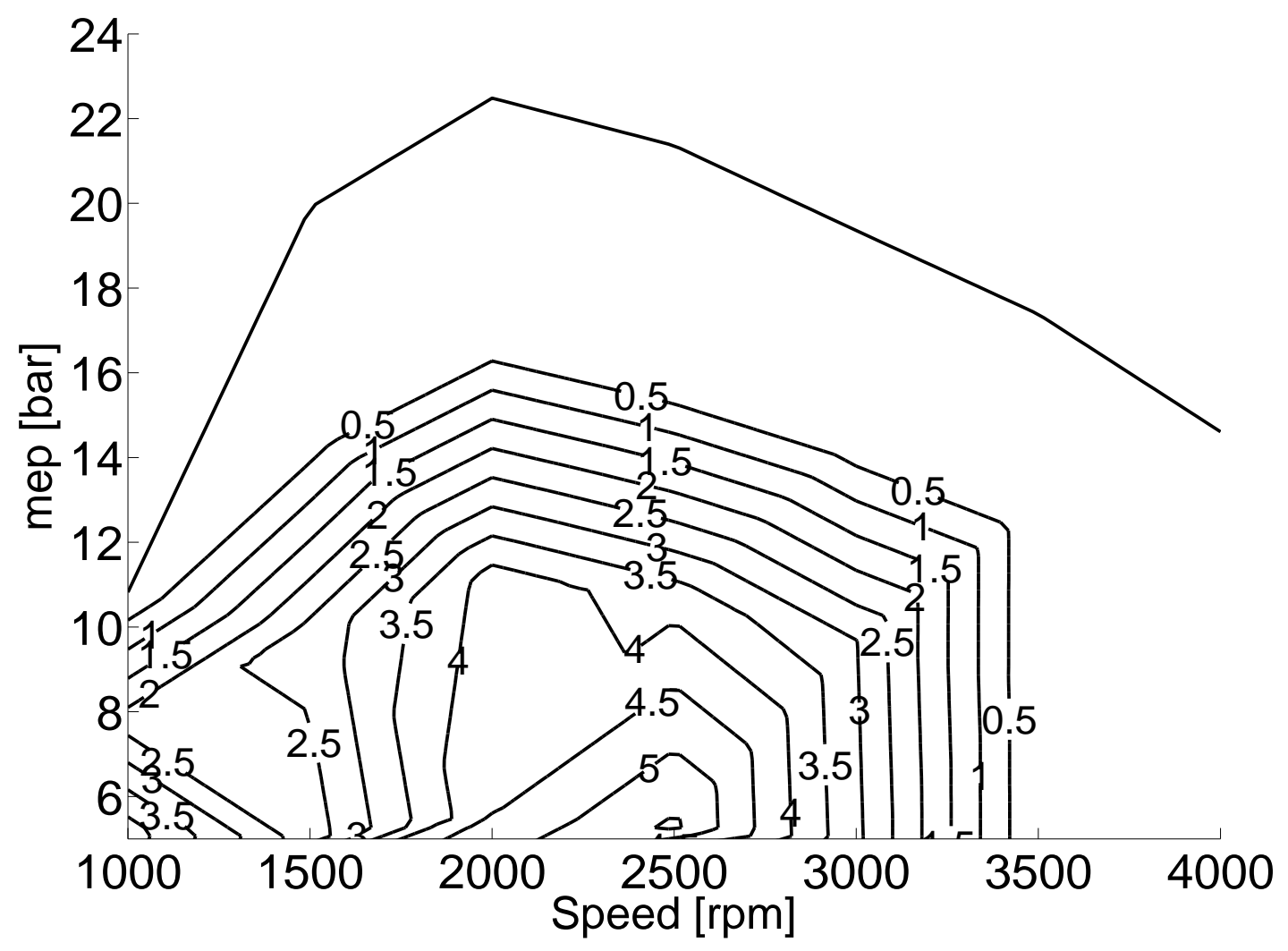

Figure 5: Heat transfer to the EGR cooling water $\left(\dot{Q}_{E G R}\right)\left[\% \dot{m}_{f} H_{v}\right]$ 


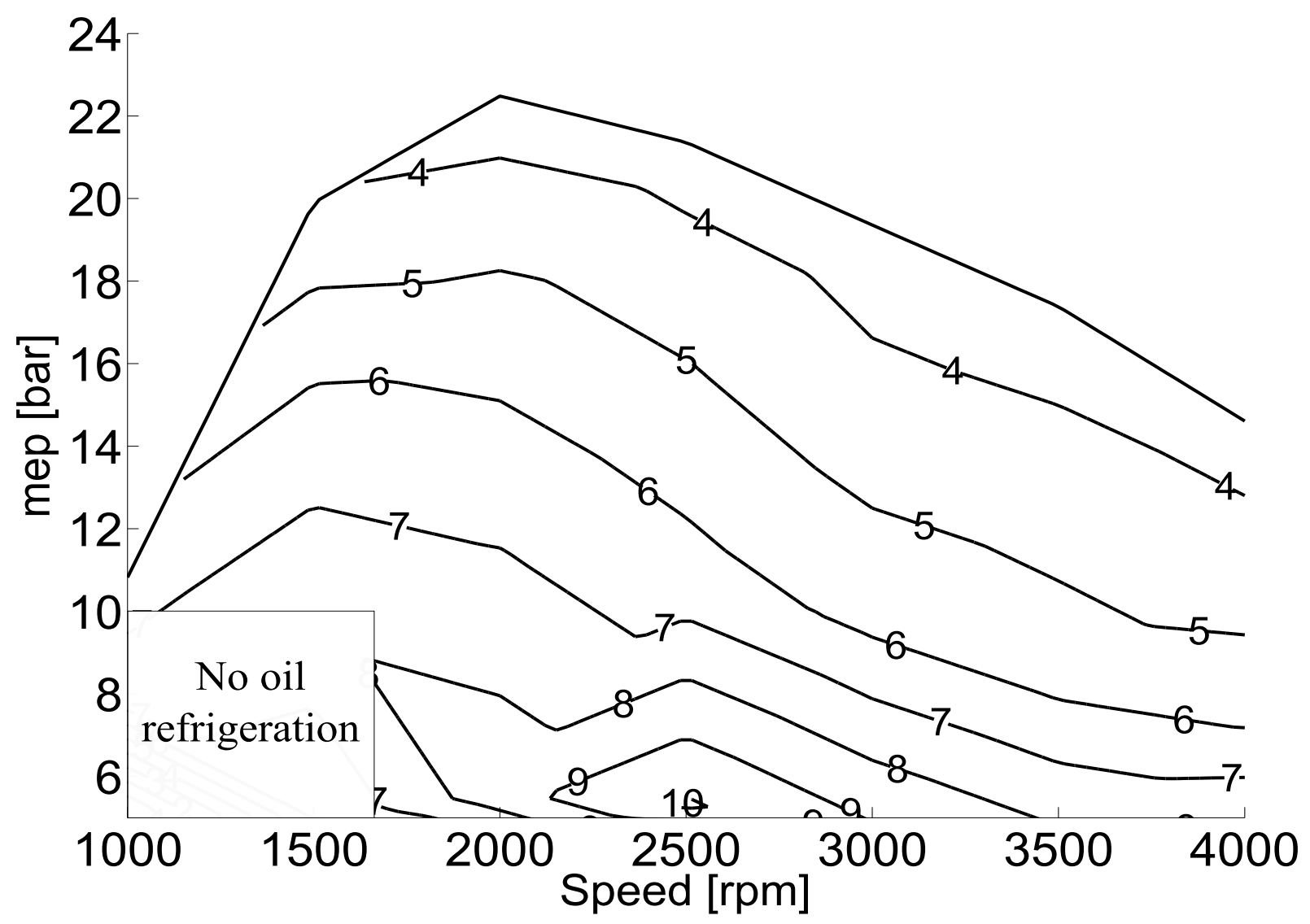

Figure 6: Heat transfer to the oil $\left(\dot{Q}_{o i l}\right)\left[\% \dot{m}_{f} H_{v}\right]$ 


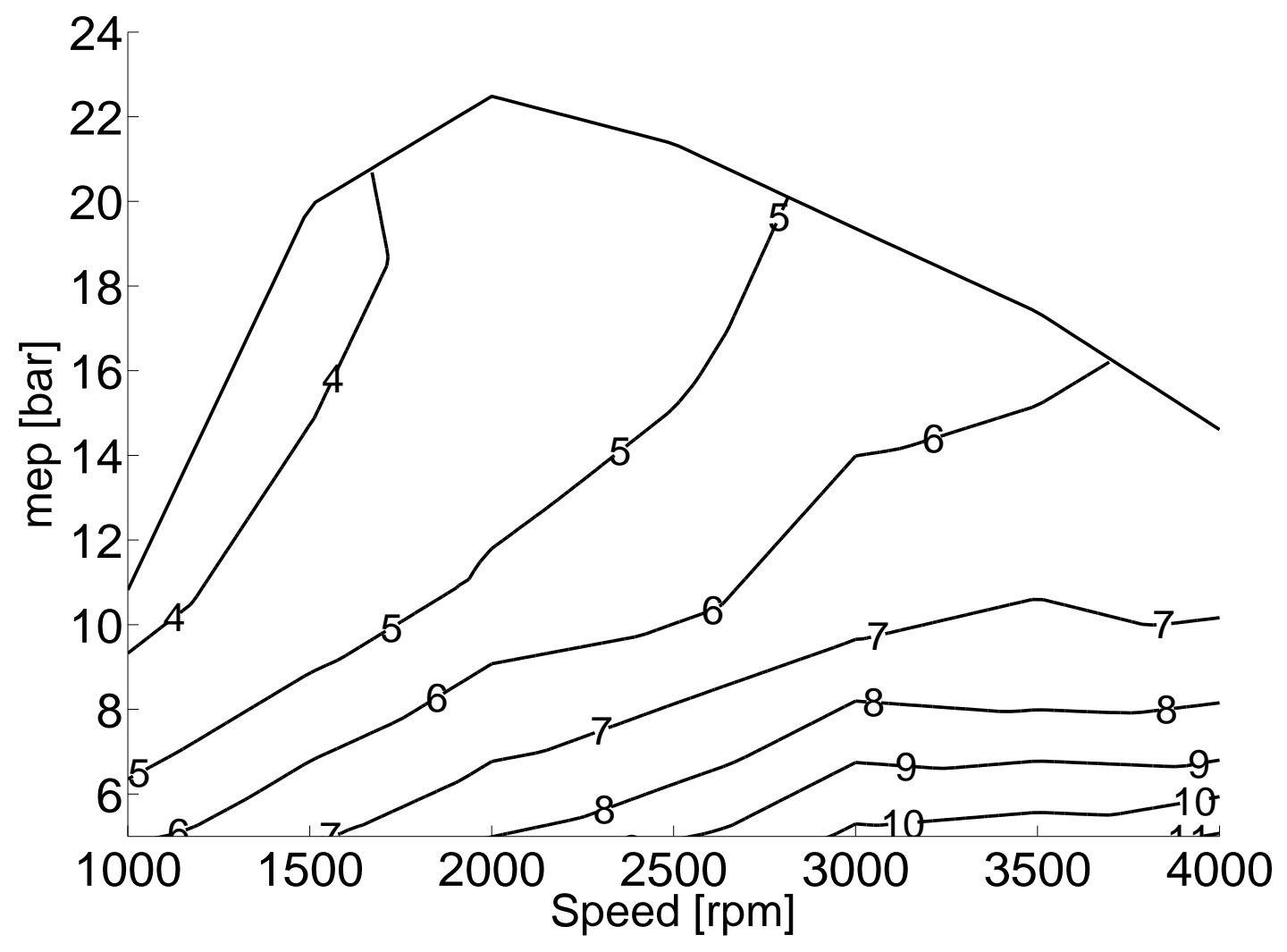

Figure 7: Ancillaries and friction $\left(N_{a}+N_{f r}\right)\left[\% \dot{m}_{f} H_{v}\right]$ 


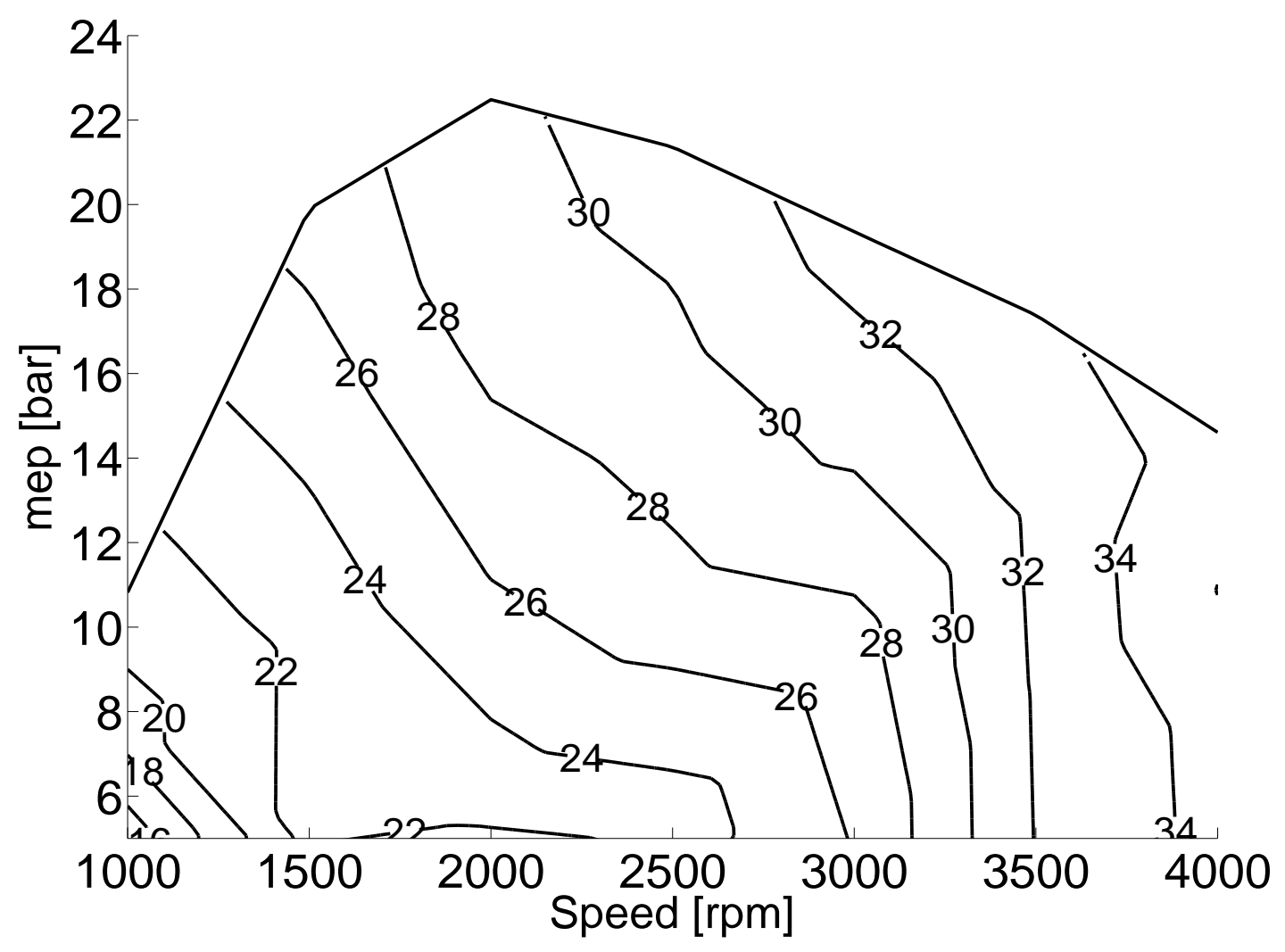

Figure 8: Exhaust gases sensible enthalpy $\left(\dot{H}_{g}\right)\left[\% \dot{m}_{f} H_{v}\right]$ 


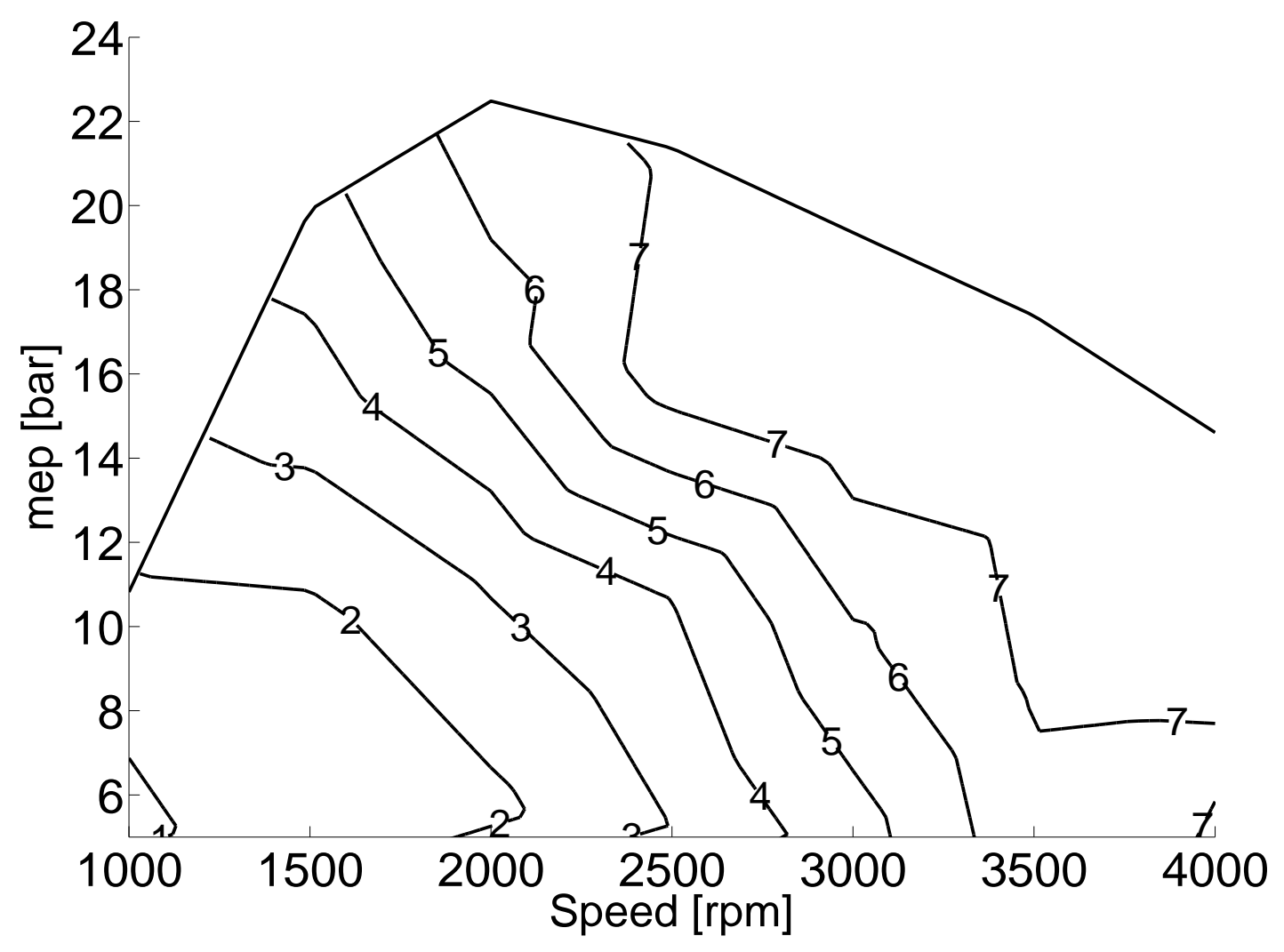

Figure 9: Heat transfer in the intercooler $\left(\dot{Q}_{a}\right)\left[\% \dot{m}_{f} H_{v}\right]$ 


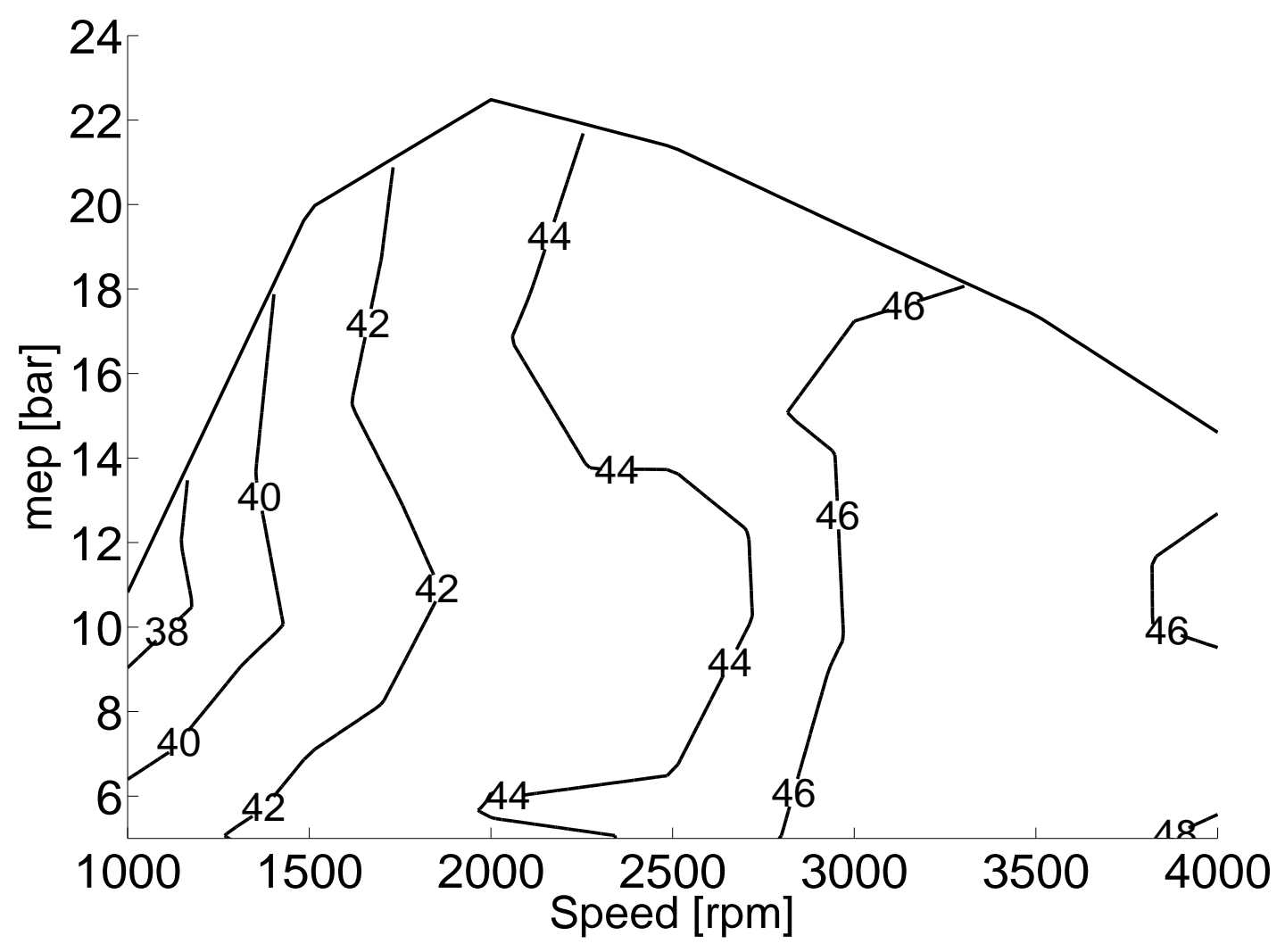

Figure 10: Indicated efficiency $\left(\eta_{i}\right)\left[\% \dot{m}_{f} H_{v}\right]$ 


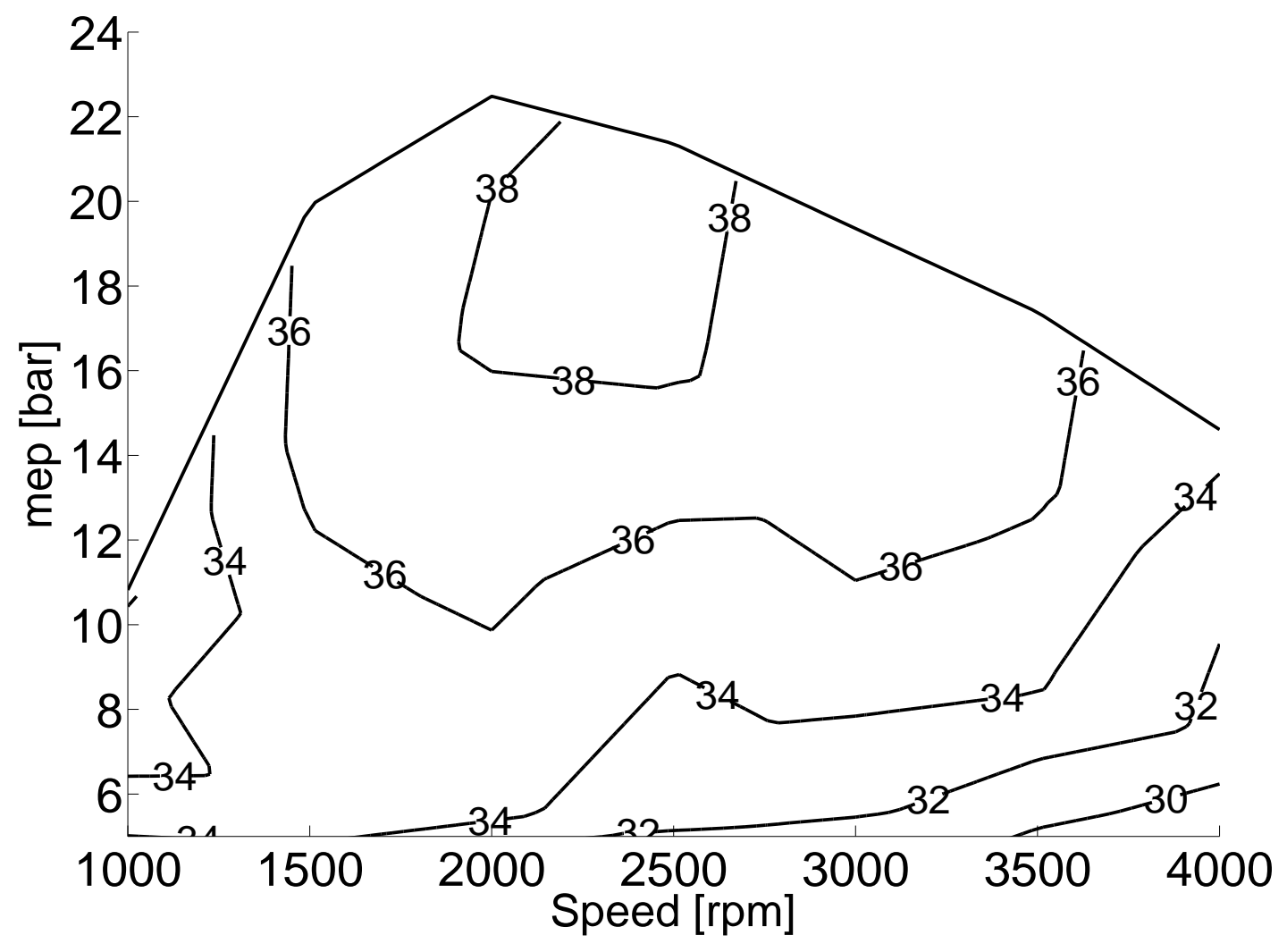

Figure 11: Brake efficiency $\left(\eta_{b}\right)\left[\% \dot{m}_{f} H_{v}\right]$ 


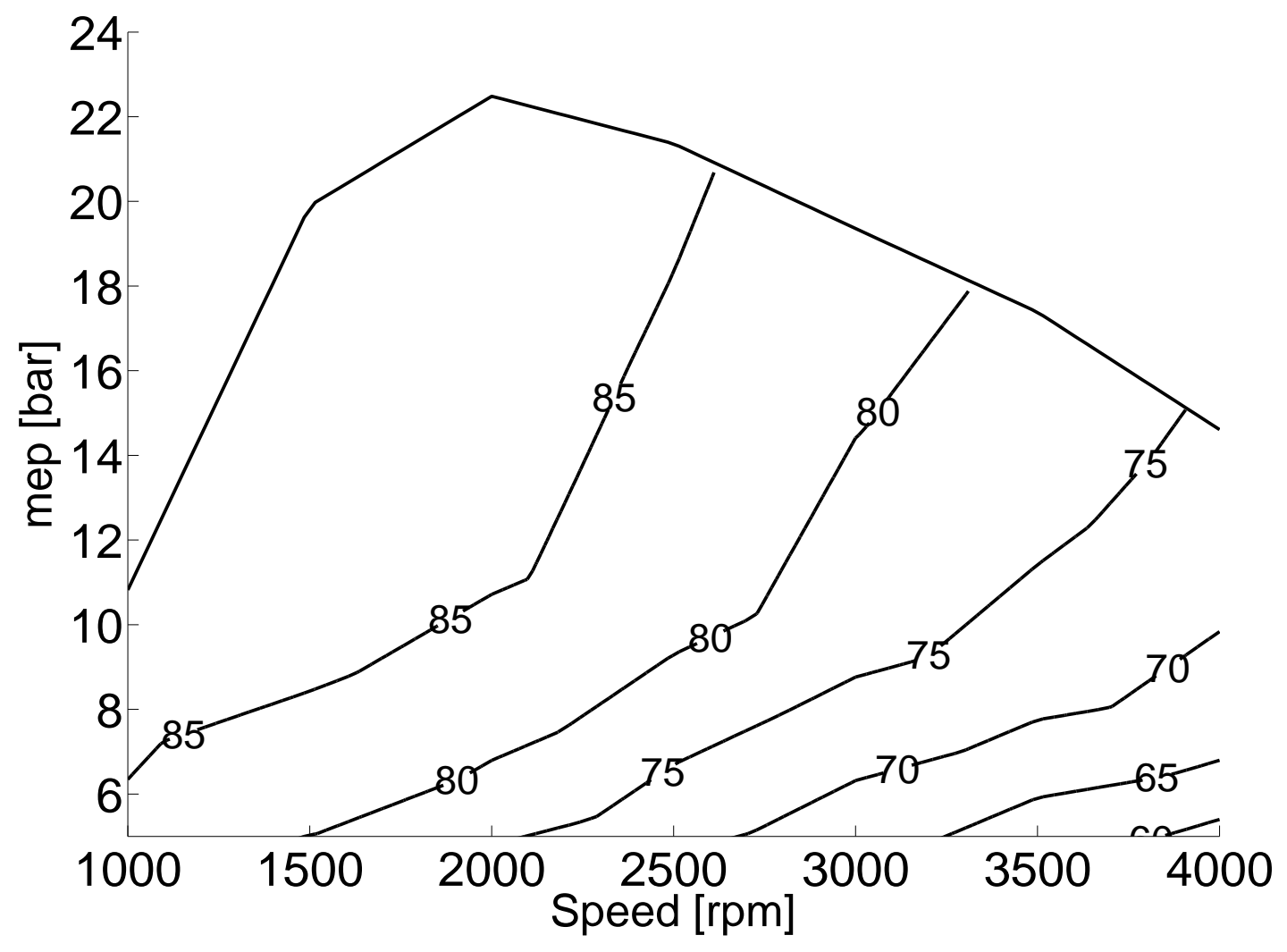

Figure 12: Mechanical efficiency $\left(\frac{N_{b}}{N_{i}} \times 100\right)$ 


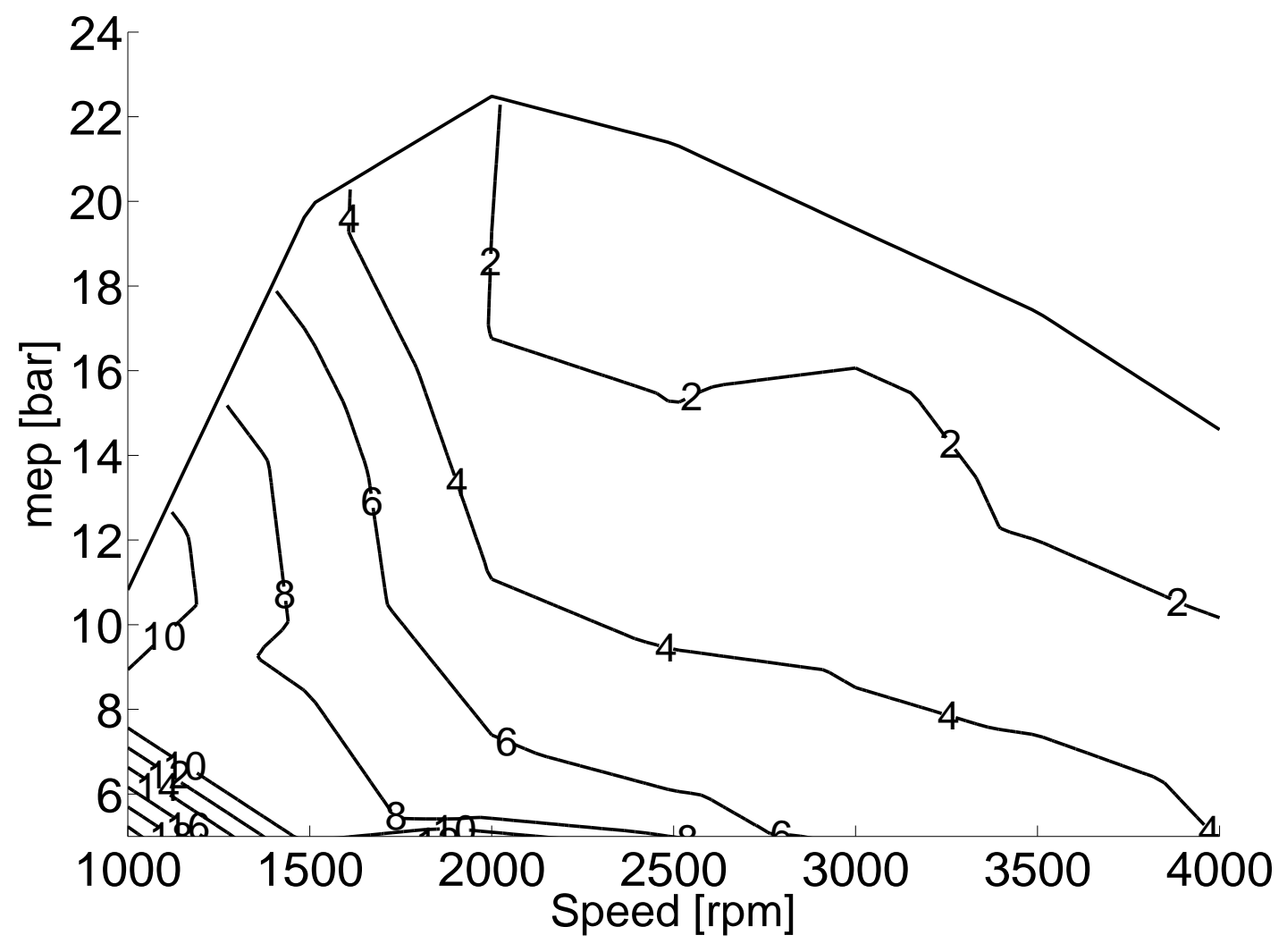

Figure 13: Miscellaneous term $\left(\dot{Q}_{m i s c}\right)\left[\% \dot{m}_{f} H_{v}\right]$ 


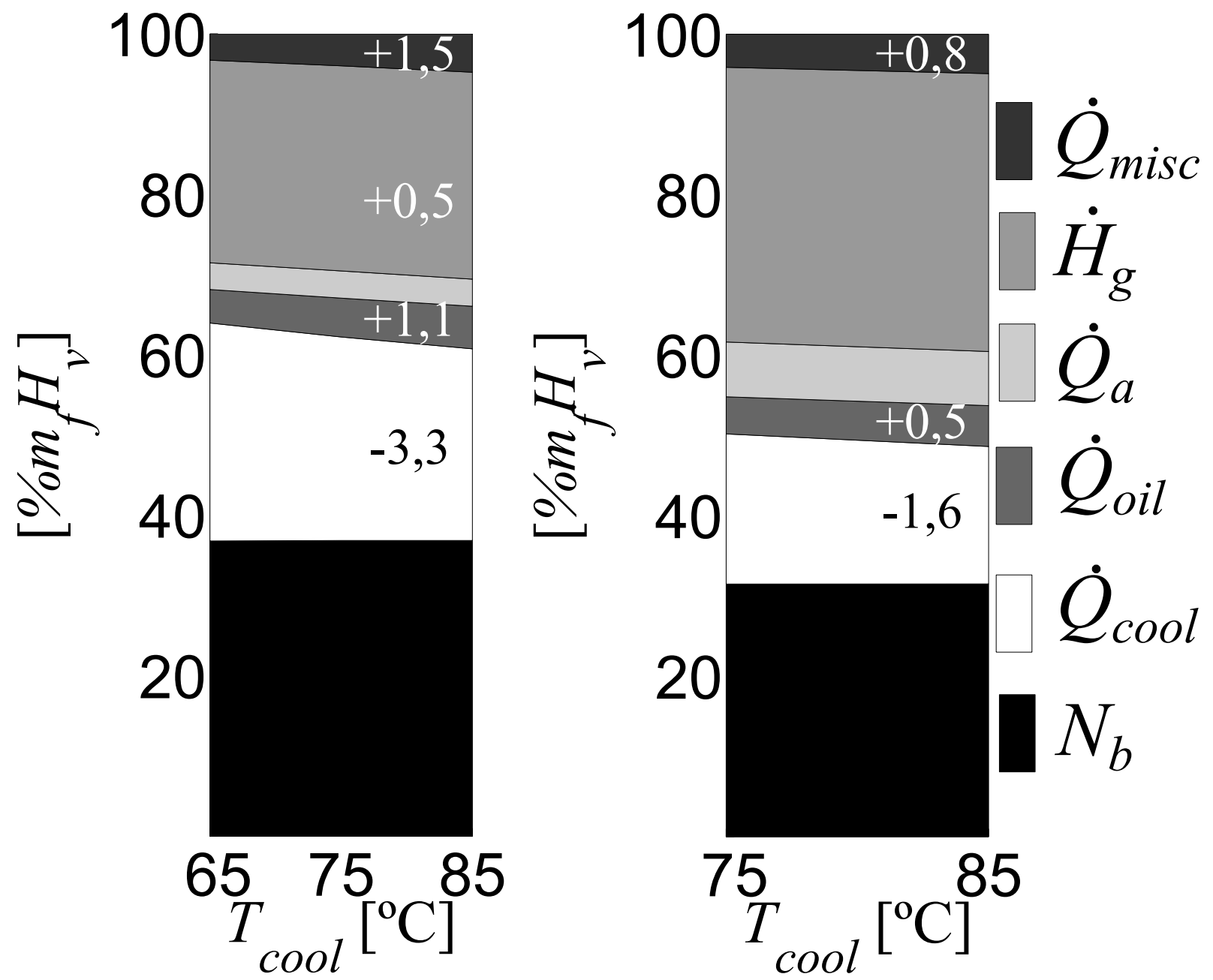

Figure 14: GEB for the coolant temperature variation in a set of $50 \%$ load operating points, left $2000 \mathrm{rpm}$, right $4000 \mathrm{rpm}$ 

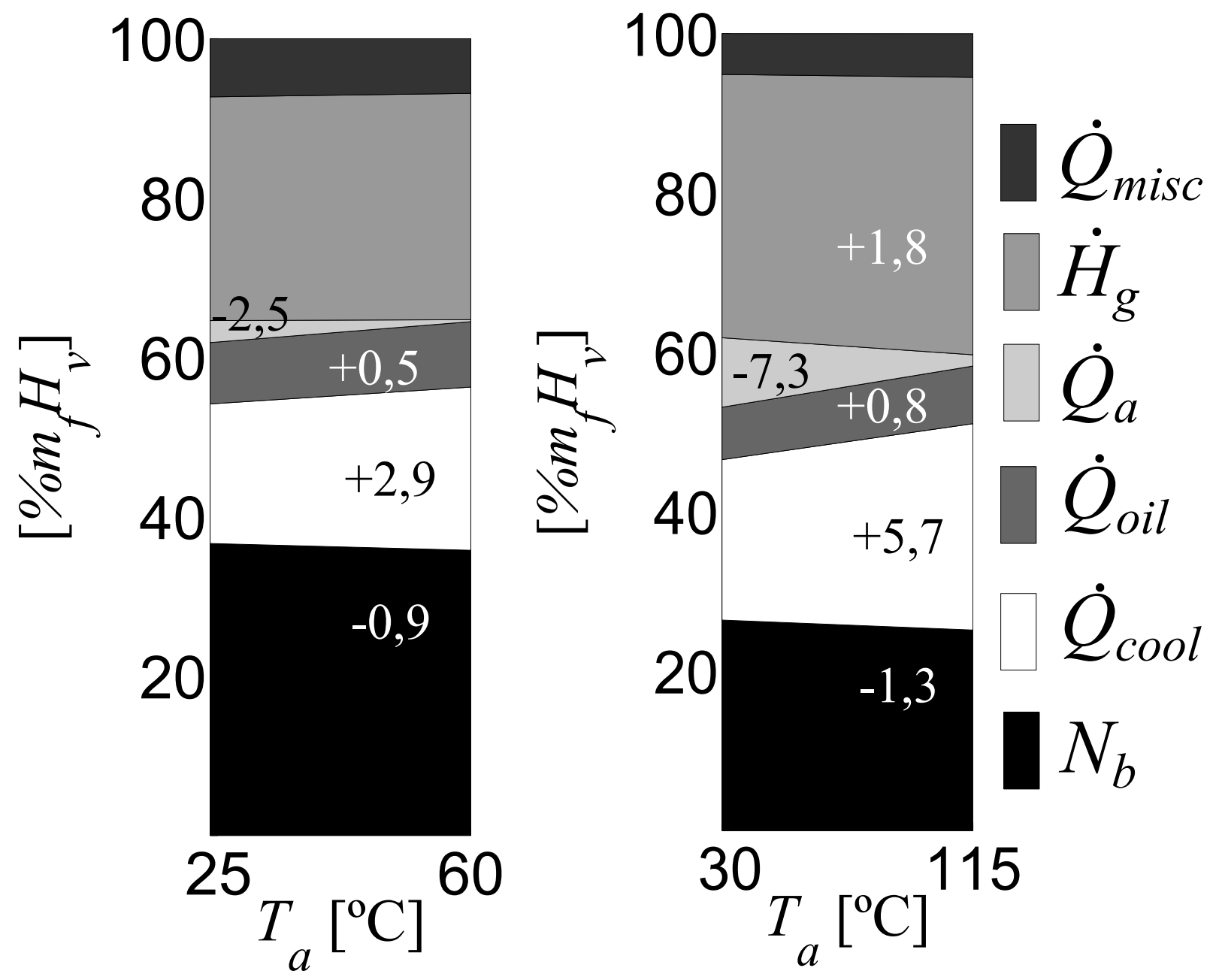

Figure 15: GEB for the intake temperature variation in a set of $25 \%$ load operating points, left $2000 \mathrm{rpm}$, right $4000 \mathrm{rpm}$ 


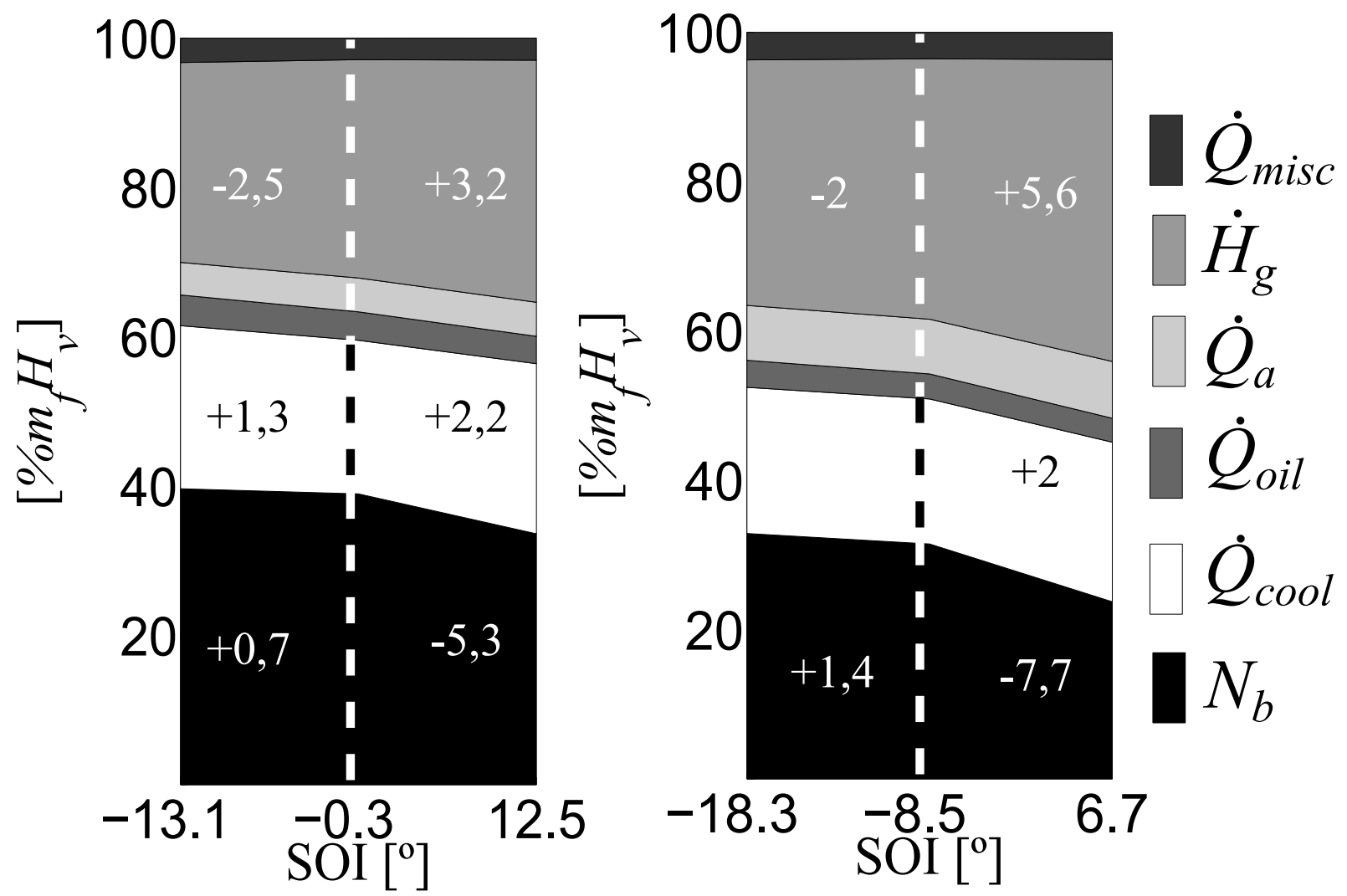

Figure 16: GEB for the SOI variation in a set of 50\% load operating points, left $2000 \mathrm{rpm}$, right $4000 \mathrm{rpm}$ 


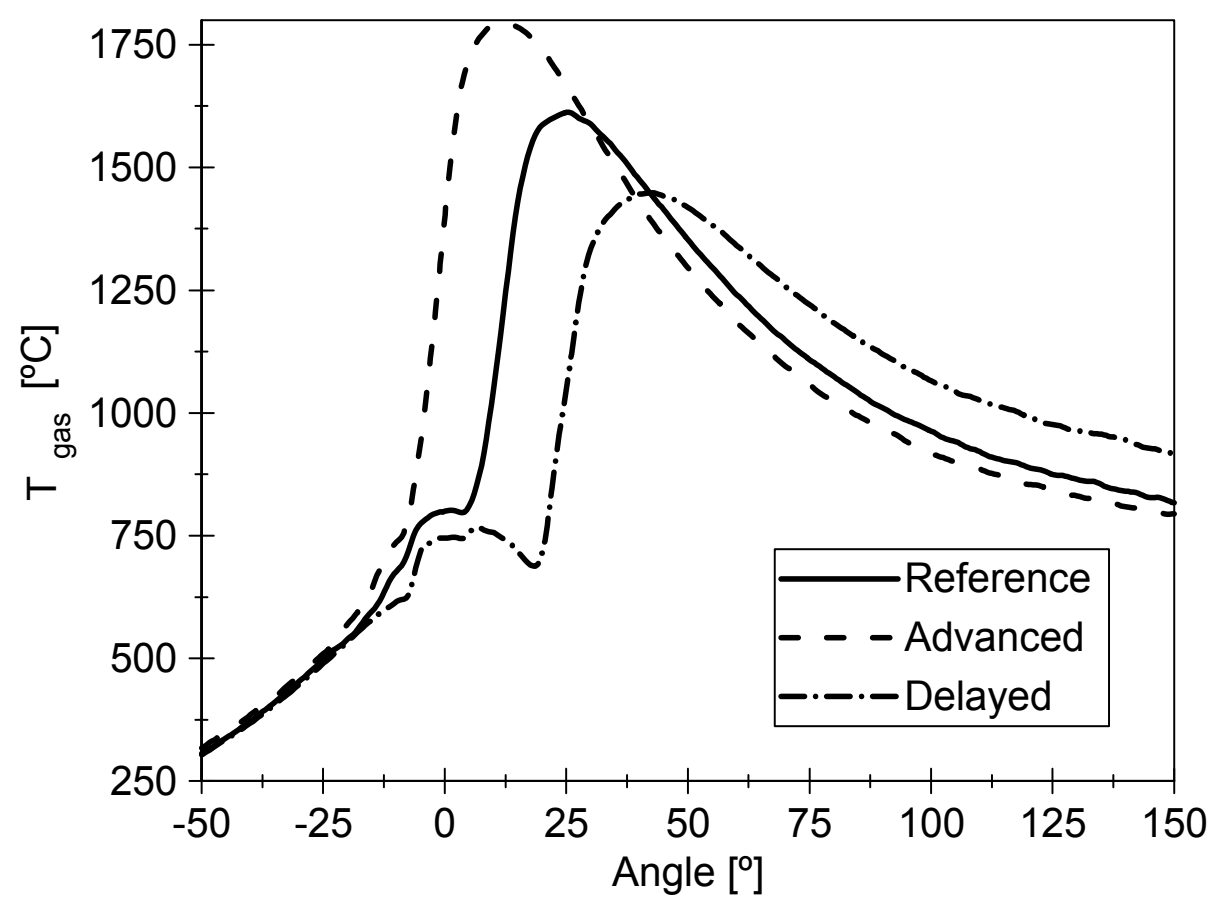

Figure 17: Gas Temperature due to a SOI variation of $\pm 13^{\circ}$ at $2000 \mathrm{rpm}$ and $50 \%$ Load 


\section{Tables}

Table 1. Tested Engine technical data

Table 2. Test cell instrumentation

Table 3. Measurement set

Table 4. Energy terms variation $\left[\% m_{f} H_{v}\right]$ 
Table 1: Tested Engine technical data

\begin{tabular}{ll}
\hline Cylinders & 4 in-line \\
Bore & $75 \mathrm{~mm}$ \\
Stroke & $88 \mathrm{~mm}$ \\
Unitary displacement & $390 \mathrm{~cm} 3$ \\
Compression ratio & $16: 1$ \\
Air management & Turbocharged \\
Maximum power & $82 \mathrm{~kW}$ at $3600 \mathrm{rpm}$ \\
Maximum torque & $270 \mathrm{Nm}$ at $1750 \mathrm{rpm}$ \\
Cycle & Diesel \\
Injection & Common rail \\
\hline
\end{tabular}


Table 2: Test cell instrumentation

\begin{tabular}{llll} 
Variable & Equipment & Range & Accuracy \\
\hline Cylinder pressure & AVL GH13P & 0 to $250 \mathrm{bar}$ & Linearity $0.3 \%$ \\
Amplifier & Kistler 5011B & $\pm 10 \mathrm{~V}$ & \\
Air mass flow & Sensiflow DN80 & 20 to $720 \mathrm{~kg} / \mathrm{h}$ & $2 \%$ \\
Fuel mass flow & AVL 733S Fuel meter & 0 to $150 \mathrm{~kg} / \mathrm{h}$ & $0.2 \%$ \\
Blow-by mass flow & AVL blow-by Meter & 1.5 to $75 \mathrm{l} / \mathrm{min}$ & $1.5 \%$ \\
Temperature & K-type Thermocouples & -200 to $1250^{\circ} \mathrm{C}$ & $1.5{ }^{\circ} \mathrm{C}$ \\
Temperature & RTD & -200 to $850^{\circ} \mathrm{C}$ & $0.2^{\circ} \mathrm{C}$ \\
Mean pressure & Kistler Piezo-resistive Pressure Transmitters & $0-10 \mathrm{bar}$ & Linearity $0.2 \%$ \\
Gases analysis & Horiba mexa & & $1-3 \%$ of full scale \\
Coolant flow & Krohne 4010 Optiflux & $\pm 12 \mathrm{~m} / \mathrm{s}$ & $0.1 \%$ of full scale \\
Oil exchanger cooling & Isoil MS500 & $0-1036 \mathrm{l} / \mathrm{h}$ & $0.5 \%$ of full scale \\
Fuel exchanger cooling & Yoko AdmagAE208MG & $0-10 \mathrm{~m} / \mathrm{s}$ & $0.5 \%$ \\
Turbo oil mass flow & Krohne Optimass 3050C & $450 \mathrm{~kg} / \mathrm{h}(\mathrm{max})$ & $0.5 \%$ \\
\hline
\end{tabular}


Table 3: Measurement set

\begin{tabular}{|c|c|c|}
\hline a) Engine map & Range & Step \\
\hline Speed & 1000 to $4000 \mathrm{rpm}$ & $500 \mathrm{rpm}$ \\
\hline Load & 25 to $100 \%$ & $25 \%$ \\
\hline$T_{\text {cool }}$ & $85^{\circ} \mathrm{C}$ & - \\
\hline$T_{o i l}$ & 90 up to $120^{\circ} \mathrm{C}$ (Oil cooler fully open) & - \\
\hline$T_{a}$ & $30^{\circ} \mathrm{C}$ & - \\
\hline b) Coolant and Oil temperature variations & Range & Step \\
\hline Speed & 1000 to $4000 \mathrm{rpm}$ & $1000 \mathrm{rpm}$ \\
\hline Load & 25 to $75 \%$ & $25 \%$ \\
\hline$T_{\text {cool }}$ & 65 to $85^{\circ} \mathrm{C}$ & $10^{\circ} \mathrm{C}$ \\
\hline$T_{\text {oil }}$ & 90 to $100^{\circ} \mathrm{C}$ & $5^{\circ} \mathrm{C}$ \\
\hline$T_{a}$ & $30^{\circ} \mathrm{C}$ & - \\
\hline c) Intake air temperature variations & Range & Step \\
\hline Speed & 2000 to $4000 \mathrm{rpm}$ & $1000 \mathrm{rpm}$ \\
\hline Load & $25 \%$ & - \\
\hline$T_{\text {cool }}$ & $85^{\circ} \mathrm{C}$ & - \\
\hline$T_{\text {oil }}$ & $90^{\circ} \mathrm{C}$ & - \\
\hline$T_{a}$ & $25^{\circ} \mathrm{C}$ to $115^{\circ} \mathrm{C}$ (Intercooler fully open and closed) & - \\
\hline d) SOI variation & Range & Step \\
\hline Speed & 1000 to $4000 \mathrm{rpm}$ & $1000 \mathrm{rpm}$ \\
\hline Load & $50 \%$ & - \\
\hline$T_{\text {cool }}$ & $85^{\circ} \mathrm{C}$ & - \\
\hline$T_{o i l}$ & 90 & - \\
\hline$T_{a}$ & $30^{\circ} \mathrm{C}$ & - \\
\hline SOI & Nominal $\pm 13^{\circ}$ & $\pm 13^{\circ}$ \\
\hline
\end{tabular}


Table 4: Energy terms variation $\left[\% m_{f} H_{v}\right]$

a) Effect of coolant and oil temperature variation (each $20^{\circ} \mathrm{C}$ )

\begin{tabular}{c|ccccccccc} 
speed [rpm] & $\Delta \eta_{i, N}$ & $\Delta\left(N_{a}+N_{f r}\right)_{N}$ & $\Delta N_{p, N}$ & $\Delta \eta_{b, N}$ & $\Delta \dot{Q}_{c o o l, N}$ & $\Delta \dot{Q}_{\text {oil, }}$ & $\Delta \dot{Q}_{a, N}$ & $\Delta \dot{H}_{g, N}$ & $\Delta \dot{Q}_{m i s c, N}$ \\
\hline 2000 & -0.3 & -0.3 & 0.1 & 0.1 & -3.3 & 1.1 & 0.1 & 0.5 & 1.5 \\
4000 & -0.4 & -0.3 & 0.1 & 0.0 & -3.2 & 0.9 & -0.2 & 0.8 & 1.6
\end{tabular}

b) Effect of intake air temperature variation (each $35^{\circ} \mathrm{C}$ )

\begin{tabular}{c|ccccccccc} 
speed [rpm] & $\Delta \eta_{i, N}$ & $\Delta\left(N_{a}+N_{f r}\right)_{N}$ & $\Delta N_{p, N}$ & $\Delta \eta_{b, N}$ & $\Delta \dot{Q}_{\text {cool }, N}$ & $\Delta \dot{Q}_{o i l, N}$ & $\Delta \dot{Q}_{a, N}$ & $\Delta \dot{H}_{g, N}$ & $\Delta \dot{Q}_{m i s c, N}$ \\
\hline 2000 & -0.7 & 0.0 & 0.2 & -0.9 & 3.0 & 0.5 & -2.5 & 0.3 & -0.4 \\
4000 & -0.7 & -0.2 & 0.0 & -0.5 & 2.4 & 0.3 & -3.0 & 0.7 & 0.2
\end{tabular}

c) Effect of advancing the SOI (each $13^{\circ}$ )

\begin{tabular}{c|ccccccccc} 
speed [rpm] & $\Delta \eta_{i}$ & $\Delta N_{f r}$ & $\Delta N_{p}$ & $\Delta \eta_{b}$ & $\Delta \dot{Q}_{\text {cool }}$ & $\Delta \dot{Q}_{\text {oil }}$ & $\Delta \dot{Q}_{a}$ & $\Delta \dot{H}_{g}$ & $\Delta \dot{Q}_{\text {misc }}$ \\
\hline 2000 & 1.4 & 0.6 & -0.1 & 0.7 & 1.3 & 0.3 & -0.2 & -2.5 & 0.4 \\
4000 & 1.6 & 0.2 & 0.0 & 1.4 & 0.2 & 0.3 & 0.0 & -2.0 & 0.1
\end{tabular}

d) Effect of Delaying the SOI (each $13^{\circ}$ )

\begin{tabular}{c|ccccccccc} 
speed [rpm] & $\Delta \eta_{i}$ & $\Delta N_{f r}$ & $\Delta N_{p}$ & $\Delta \eta_{b}$ & $\Delta \dot{Q}_{\text {cool }}$ & $\Delta \dot{Q}_{\text {oil }}$ & $\Delta \dot{Q}_{a}$ & $\Delta \dot{H}_{g}$ & $\Delta \dot{Q}_{\text {misc }}$ \\
\hline 2000 & -5.8 & -0.3 & 0.1 & -5.3 & 2.2 & -0.1 & 0.0 & 3.2 & 0.1 \\
4000 & -8.3 & -0.6 & -0.1 & -7.7 & 2.0 & -0.2 & 0.3 & 5.6 & 0.1 \\
\hline
\end{tabular}

